UCRL-ID-119658

\title{
Forensic Radiochemistry of PUBLIC Site Inspection Samples
}

\author{
Kenton J. Moody \\ Nuclear Science Applications Section \\ Isotope Sciences Division \\ Chemistry \& Materials Science
}

January 5, 1995

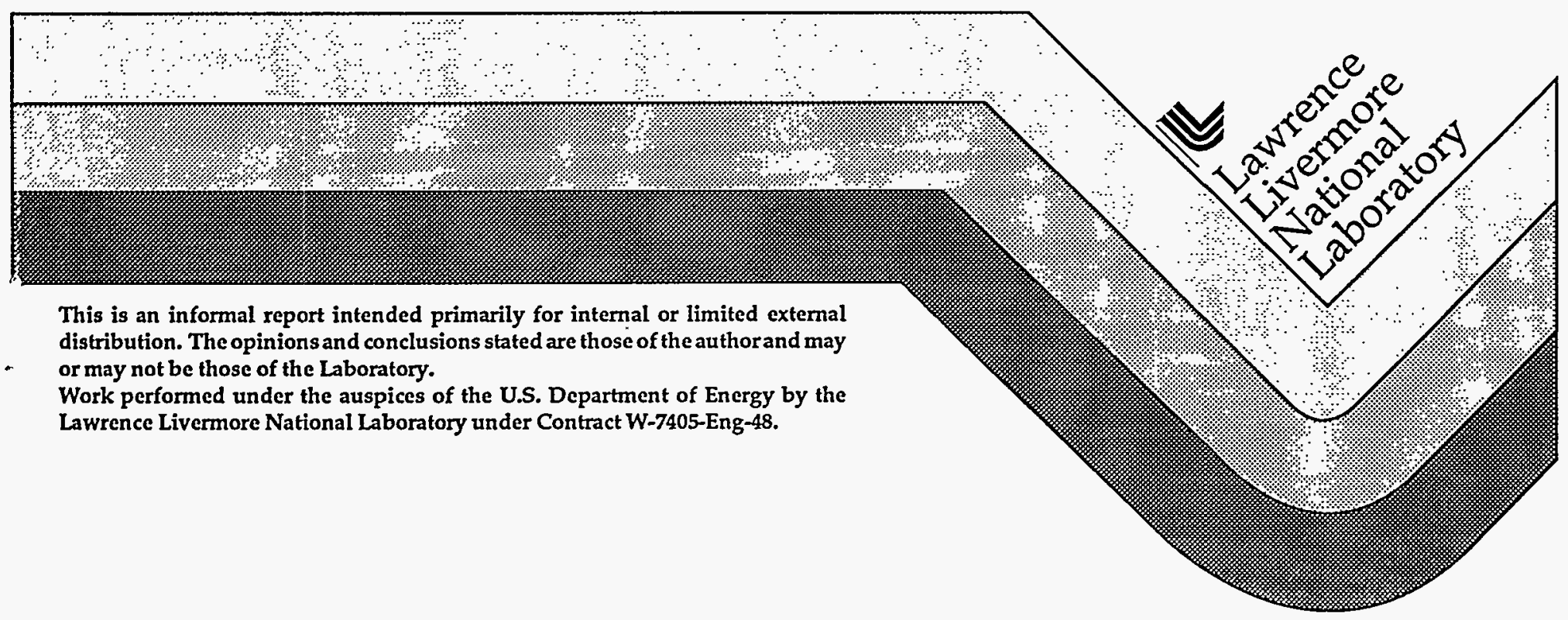




\section{DISCLAIMER}

This document was prepared as an account of work sponsored by an agency of the United States Government. Neither the United States Government nor the University of California nor any of their employees, makes any warranty, express or implied, or assumes any legal liability or responsibility for the accuracy, completeness, or usefulness of any information, apparatus, product, or process disclosed, or represents that its use would not infringe privately owned rights. Reference herein to any specific commercial products, process, or service by trade name, trademark, manufacturer, or otherwise, does not necessarily constitute or imply its endorsement, recommendation, or favoring by the United States Government or the University of California. The views and opinions of authors expressed herein do not necessarily state or reflect those of the United States Government or the University of California, and shall not be used for advertising or product endorsement purposes.

This report has been reproduced directly from the best available copy.

Available to DOE and DOE contractors from the Office of Scientific and Technical Information

P.O. Box 62, Oak Ridge, TN 37831

Prices available from (615) 576-8401

Available to the public from the

National Technical Information Service

U.S. Department of Commerce 5285 Port Royal Rd. Springfield, VA 22161

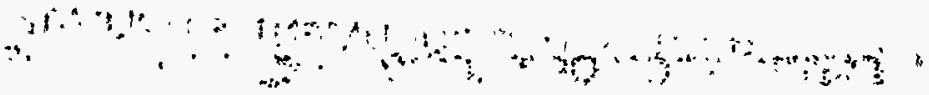




\section{DISCLAIMER}

Portions of this document may be illegible in electronic image products. Images are produced from the best available original document. 


\title{
Forensic Radiochemistry of PUBLIC Site Inspection Samples
}

\author{
Kenton J. Moody \\ Isotope Sciences Division \\ Lawrence Livermore National Laboratory \\ Livermore, CA 94551
}

\section{INTRODUCTION}

For the past two years, the Isotope Sciences Division (formerly Nuclear Chemistry) has been developing a program to extract forensic information from samples of plutonium or highly-enriched uranium. In the case of $\mathrm{Pu}$, it is possible to determine the date of chemical separation, the date of its casting as metal, the enrichment of the uranium starting material, the length and perhaps other details (neutron spectrum and fluence) of reactor irradiation, the reprocessing technique, and clues to the identity of a specific facility. For enriched uranium, information is possible on the detailed timeline of material production, including the date of enrichment, whether the plant feed was formerly-irradiated uranium, the date of final purification; and facility-specific clues. For more information, see "Dissolved Oralloy Standards and the Origin of HEU", by Ken Moody, LLNL report UCRL-ID-117611, April 13, 1994.

It would be valuable to be able to apply the same techniques to materials of opportunity associated with clandestine or illicit nuclear weapons production. However, interpretation of the radionuclide contents of dilute samples containing small or finely-divided amounts of $\mathrm{Pu}$ and $\mathrm{U}$ is more complicated than a similar analysis of a bulk sample; the isotopics of the sample may be associated more with the plant waste stream than with product, and chemical effects of the environment after dispersal of the sample alter its properties. Nevertheless, it was decided to analyze interesting samples associated with the U.S. weapons production facilities and determine how much forensic information was contained therein. In support of this endeavor, samples from the recent PUBLIC site inspections of two uranium enrichment facilities were obtained.

It is possible that the U.S. gaseous diffusion facilities at Portsmouth, $\mathrm{OH}$ and Paducah, KY will be subject to international inspections for safeguards and accountability purposes. The question arose whether an inspector with a covert agenda could surreptitiously learn classified information from the analysis of process debris found at these sites. To explore that possibility, the LLNL Forensic Science Center (FSC) was asked to undertake "counter-forensic" sampling in order to evaluate the potential magnitude of the risk to classified technology. Project PUBLIC (Portsmouth/Paducah Uranium Barrier: Livermore Investigative Campaign) was designed to apply state-of-the-art analytical technologies to interrogate wipes and other samples from areas of the plants where converters were disassembled or barrier was destroyed. 
While the radiochemical analysis given in this report does not relate directly to the original purpose of PUBLIC, collateral radioanalytical chemistry provides background information about the activities at the plants and the time scale of the operations. Such knowledge could prove valuable in placing deductions about the diffusion barrier within a context that might support the conclusions that are drawn. As a result, this work also appears as a chapter in the final (classified) PUBLIC report ("Project PUBLIC: Counter-forensic Investigation of U.S. Gaseous Diffusion Plants", E. Randich et al.,1995; in process).

\section{SAMPLE SELECTION}

While the PUBLIC inspection team had no prior knowledge of the classified aspects of the diffusion barrier, they did have the unclassified information that the barrier material was formed by sintering a nickel powder. Thus, while several samples were collected by scraping loose debris into plastic bottles with spatulas, or by wiping interesting surfaces with moist filter paper, most of the samples were collected magnetically. The team concentrated on collecting specimens from confined or sheltered areas where debris could have collected over a period of years.

A total of approximately forty samples were collected in the two site inspections. These samples were returned to LLNL where they were subjected to an initial prescreening (including a radiation survey, an X-ray fluorescence measurement, and examination under an optical microscope) to identify potential barrier materials. Samples containing significant amounts of nickel were divided into two or more subsamples by segregating dissimilar debris components.

The radiochemical analyses are labor-intensive; it was therefore impossible to even consider treating most of the 69 samples generated by PUBLIC. Furthermore, the analyses are destructive, resulting in the total consumption of the selected samples. Consequently, it was decided that no more than five samples would be radiochemically analyzed, and that only one of these samples would be a "pure" Ni specimen selected as candidate diffusion barrier material. The chosen samples would have fairly high radioactivity contents, as measured by initial sample prescreening. With these considerations, the specimens listed in Table 1 were selected. 
Table 1. Samples Selected for Radiochemical Analyses, Portsmouth and Paducah Site Inspections.

\begin{tabular}{|c|c|c|}
\hline Sample I.D, & Weight & Description \\
\hline $94-7-14(\mathrm{PO}-7)$ & $7.0 \mathrm{~g}$ & $\begin{array}{l}\text { Ni flakes collected with a spatula } \\
\text { into a polyvial; from Building X-705 } \\
\text { catwalk; Portsmouth. }\end{array}$ \\
\hline $94-7-17$ (PO-9) & $1.4 \mathrm{~g}$ & $\begin{array}{l}\text { Magnetic flakes, both rust and } \mathrm{Ni} \text {, } \\
\text { collected from the top of an I-beam } \\
\text { approximately } 10 \text { feet from the floor; } \\
\text { Building X-705, basement cutting area, } \\
\text { east wall; Portsmouth. }\end{array}$ \\
\hline $94-7-19(\mathrm{PO}-11)$ & $3.3 \mathrm{~g}$ & $\begin{array}{l}\text { Magnetic grit, mostly Fe, collected } \\
\text { from groove in floor around railroad } \\
\text { tracks; Building X-705; Portsmouth. }\end{array}$ \\
\hline $94-7-38(\mathrm{PK}-4)$ & $4.9 \mathrm{~g}$ & $\begin{array}{l}\text { Loose debris, perhaps some Ni } \\
\text { flakes, collected with spatula from } \\
\text { bracket on support E8, approximately } \\
15 \mathrm{ft} \text { from floor; Building C-400; } \\
\text { Paducah. }\end{array}$ \\
\hline $94-7-45(\mathrm{PK}-7)$ & $20.5 \mathrm{~g}$ & $\begin{array}{l}\text { Magnetic grit, with most of the } \mathrm{Ni} \\
\text { removed, collected along concrete/ } \\
\text { transite interface, about } 8 \text { feet from } \\
\text { floor; radioactive waste area, Building } \\
\text { C-400; Paducah. }\end{array}$ \\
\hline Blank (X) & $4.7 \mathrm{~g}$ & $\begin{array}{l}\text { Radiochemistry blank constructed from } \\
2.93 \mathrm{~g} \mathrm{Fe}_{2} \mathrm{O}_{3}+1.73 \mathrm{~g} \mathrm{Ni}_{2} \mathrm{O}_{3} \cdot \mathrm{xH}_{2} \mathrm{O}(77.0 \% \mathrm{Ni}) \\
+0.055 \mathrm{~g} \mathrm{CaO}\end{array}$ \\
\hline
\end{tabular}

Sample 94-7-14 was very rich in candidate barrier material, and was the source of 94-7-15, which was extensively analyzed and is described in detail in the PUBLIC report. The Blank sample was constructed to check for cross contamination among the samples during the analyses; it was treated with the same reagents at the same time as the other samples, and should return completely negative results for radionuclide content.

\section{SAMPLE DISSOLUTION AND XRE RESULTS}

As the first step, a sample must be totally dissolved. The dissolution must be complete to avoid fractionating the elements from one another (which can result in improper age determinations) and to yield a uniform sample that can be quantitatively analyzed for gamma-ray emission and by XRF. As anticipated, the dissolution of samples containing nickel, iron, dirt, paint flakes, plastic shards, oil, broken glass, hair, and (in one case) a dead insect, can be formidable. The following procedure was used on the PUBLIC samples: 
The samples were poured into Erlenmeyer "reaction" flasks, and the original sample containers were sequentially washed with water and with $8 \mathrm{M} \mathrm{HNO}_{3}$ to ensure quantitative transfer. Samples were heated gently until reaction was complete. A few drops of $9 \mathrm{M} \mathrm{HCl}$ were added to each reaction flask, and the samples were gently evaporated to moist residues. Several times over the next few days, $9 \mathrm{M} \mathrm{HCl}$ was added to the samples, which were then evaporated to moist residues. $4 \mathrm{M} \mathrm{HCl}$ was added to each sample, and the supernatant solutions were filtered through Whatman \#42 paper into fresh Erlenmeyer flasks which were to serve as primary containers for the analytical solutions. Several times over the next two days, $8 \mathrm{M} \mathrm{HNO}_{3}$ was added to the residues in the reaction flasks, which were evaporated to moist deposits. Next, $2 \mathrm{ml}$ of $7.5 \mathrm{M} \mathrm{HClO}_{4}$ and several $\mathrm{ml}$ of $8 \mathrm{M}$ $\mathrm{HNO}_{3}$ were added to each flask, and the resultant mixtures were evaporated until the evolution of perchloric fumes was observed. $4 \mathrm{M} \mathrm{HCl}$ was added to the samples, and the supernatant solutions were filtered into the Erlenmeyer primary containers. Several $\mathrm{ml}$ of $8 \mathrm{M} \mathrm{HNO}_{3}$ and $1 \mathrm{ml}$ of conc $\mathrm{HF}$ were added to the residues in the reaction flasks, which were then evaporated to moist deposits. Three $\mathrm{ml}$ of $7.5 \mathrm{M} \mathrm{HClO}_{4}$ were then added to each reaction flask, and the samples were evaporated through perchloric fumes to dryness. The reaction flasks were then heated vigorously with a Bunsen burner to volatilize $\mathrm{SiF}_{4}$. Several $\mathrm{ml}$ of $4 \mathrm{M}$ $\mathrm{HCl}$ were added to each flask, and the resultant solutions were filtered into the Erlenmeyer pots. The filter papers were washed with $4 \mathrm{M} \mathrm{HCl}$, and were removed from the funnels and placed into the appropriate reaction flasks. Several $\mathrm{ml}$ of $8 \mathrm{M} \mathrm{HNO}_{3}$ and $2 \mathrm{ml}$ of $7.5 \mathrm{M} \mathrm{HClO}_{4}$ were added to each flask and the samples were heated until the filter papers were destroyed with the evolution of copious perchloric fumes. The contents of the flasks were quantitatively transferred to centrifuge cones with $4 \mathrm{M} \mathrm{HCl}$, the solutions were centrifuged, and the supernates carefully decanted into the primary containers.

Four of the six samples were completely dissolved, but several milligrams of intractable white powder remained of samples 94-7-38 and 94-7-45 (the two Paducah specimens). XRF showed that this material was mostly titanium, with some minor zirconium, and was therefore probably residual paint chips. It was decided to treat these residues separately from the bulk samples, under the assumption that only a small fraction of the total radionuclide content was entrained in the precipitates. The residues were transferred to Ni crucibles with a minimum amount of dilute $\mathrm{HCl}$ and were evaporated to dryness. Several grams of $\mathrm{NaOH}$ and 1 gram of $\mathrm{Na}_{2} \mathrm{O}_{2}$ were added to the crucibles, which were heated to melt the mixtures. Twenty $\mathrm{ml}$ of water were added to the molten samples; after cooling, volumes were doubled with $9 \mathrm{M} \mathrm{HCl}$ and the supernatant liquids were transferred to fresh Erlenmeyer flasks. Several $\mathrm{ml}$ of $4 \mathrm{M} \mathrm{HCl}$ were added to the residues in the crucibles; after heating for several minutes, the supernates were decanted into the flasks containing the previous solutions. The residues were heated to dryness, $0.5 \mathrm{~g}$ of $\left(\mathrm{NH}_{4}\right)_{2} \mathrm{SO}_{4}$ and $4 \mathrm{ml}$ of conc $\mathrm{H}_{2} \mathrm{SO}_{4}$ were added to each crucible, and the mixtures were heated for several hours. The resulting solutions were diluted with $4 \mathrm{M} \mathrm{HCl}$ and transferred quantitatively to the flasks containing the previous supernates. Only a trivial amount of residue was left in the 
crucibles. The titanium solutions were analyzed with an abbreviated version of the analytical procedure given below, and were found to contain less than $1 \%$ of the $\mathrm{Th}, \mathrm{U}, \mathrm{Np}$, and $\mathrm{Pu}$ determined in the main samples. Analytical results given in Table 5 (see below) for samples 94-7-38 and 94-7-45 have been corrected for these losses.

The final analytical working solutions are described in Table 2. Aliquots of 60 microliters of each solution were dried on 1-inch diameter Whatman \#541 filter papers and subjected to XRF analysis. The results for major constituents, scaled to the total solution volume, are also given in Table 2. In many cases, the sum of the measured masses of these constituents is significantly lower than that of the original sample; the reason is that $\mathrm{XRF}$ is insensitive to low-Z materials like $\mathrm{C}$, $\mathrm{Al}$, and $\mathrm{Si}$, particularly in the presence of significant amounts of $\mathrm{Cl}$ from the solvent. In the case of the Blank, however a direct comparison of the measured XRF values with the known materials input gave good agreement (1940 mg Fe measured by XRF vs. $2050 \mathrm{mg}$ added, and $1240 \mathrm{mg} \mathrm{Ni}$ measured vs. 1330 added). The explanation for the minor amounts of $\mathrm{Cu}$ and $\mathrm{Zn}$ measured in the blank is their presence as contaminants in the reagent compounds used for solution synthesis.

Table 2. Description of Dissolved Samples and XRF results. XRF uncertainties are $\pm 10 \%$.

\begin{tabular}{|c|c|c|c|}
\hline Sample I.D. & Total Volume & Color & XRF Composition \\
\hline $94-7-14$ & $70 \mathrm{ml}$ & green & $6550 \mathrm{mg} \mathrm{Ni}, 6 \mathrm{mg} \mathrm{Cu}$. \\
\hline $94-7-17$ & $75 \mathrm{ml}$ & yellow & $\begin{array}{l}725 \mathrm{mg} \mathrm{Fe}, 225 \mathrm{mg} \mathrm{Ni} \text {, } \\
4 \mathrm{mg} \mathrm{Cu}, 3 \mathrm{mg} \mathrm{Zn}, 6 \mathrm{mg} \mathrm{U} .\end{array}$ \\
\hline $94-7-19$ & $100 \mathrm{ml}$ & orange-tan & $\begin{array}{l}2220 \mathrm{mg} \mathrm{Fe}, 145 \mathrm{mg} \mathrm{Ni} \text {, } \\
68 \mathrm{mg} \mathrm{Cu}, 8 \mathrm{mg} \mathrm{Zn} \text {, } \\
4 \mathrm{mg} \mathrm{Pb}, 14 \mathrm{mg} \mathrm{U} .\end{array}$ \\
\hline $94-7-38$ & $150 \mathrm{ml}$ & orange & $\begin{array}{l}1500 \mathrm{mg} \mathrm{Fe}, 108 \mathrm{mg} \mathrm{Ni} \text {, } \\
13 \mathrm{mg} \mathrm{Cu}, 75 \mathrm{mg} \mathrm{Zn} \text {, } \\
16 \mathrm{mg} \mathrm{Pb}, 32 \mathrm{mg} \mathrm{U} .\end{array}$ \\
\hline $94-7-45$ & $215 \mathrm{ml}$ & dark brown & $\begin{array}{l}8600 \mathrm{mg} \mathrm{Fe}, 1680 \mathrm{mg} \mathrm{Ni} \text {, } \\
204 \mathrm{mg} \mathrm{Cu}, 337 \mathrm{mg} \mathrm{Zn} \text {, } \\
9 \mathrm{mg} \mathrm{Pb}, 183 \mathrm{mg} \mathrm{U} .\end{array}$ \\
\hline Blank & $75 \mathrm{ml}$ & olive & $\begin{array}{l}1940 \mathrm{mg} \mathrm{Fe}, 1240 \mathrm{mg} \mathrm{Ni} \text {, } \\
7 \mathrm{mg} \mathrm{Cu}, 1 \mathrm{mg} \mathrm{Zn.}\end{array}$ \\
\hline
\end{tabular}




\section{ALIQUOTING AND TRACING}

Aliquots of each working solution were taken for different aspects of the radiochemical analyses. The 60-microliter aliquots for XRF analysis were indicated above, and other aliquots are listed in Table 3. Gamma-spectrometry aliquots were transferred to plastic counting vials and sealed in Saran wrap. This is a standard counting geometry for LLNL's Isotope Sciences counting facility. All other samples were delivered into 40-ml centrifuge cones.

Unspiked samples were not traced with radionuclides. To "Spike Mix P" solutions were added standard aliquots containing about $175 \mathrm{dpm}{ }^{236} \mathrm{Pu}, 30 \mathrm{dpm}$ ${ }^{232} \mathrm{U}$ (with ${ }^{228} \mathrm{Th}$ and daughters in equilibrium), and $440 \mathrm{dpm}{ }^{243} \mathrm{Am}$ (with ${ }^{239} \mathrm{~Np}$

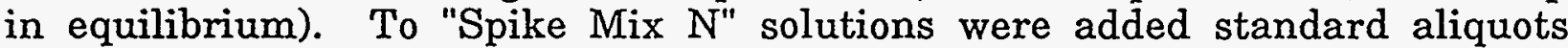
containing about $44 \mathrm{dpm}{ }^{243} \mathrm{Am}$ and $820 \mathrm{dpm}{ }^{237} \mathrm{~Np}$ (with ${ }^{233} \mathrm{~Pa}$ in equilibrium). Comparison of measurements of both spiked and unspiked samples results in chemical yield determinations and quantitative, absolute data for radionuclide atoms per ml of original solution.

Table 3. Aliquot information for radiochemical analysis.

\begin{tabular}{|c|c|c|c|c|}
\hline Sample I.D. & Gamma-Spec & Unspiked & Spike Mix P & Spike Mix N \\
\hline $94-7-14$ & $25 \mathrm{ml}$ & $15 \mathrm{ml}$ & $10 \mathrm{ml}$ & $10 \mathrm{ml}$ \\
\hline $94-7-17$ & $25 \mathrm{ml}$ & $20 \mathrm{ml}$ & $10 \mathrm{ml}$ & $10 \mathrm{ml}$ \\
\hline $94-7-19$ & $25 \mathrm{ml}$ & $20 \mathrm{ml}$ & $20 \mathrm{ml}$ & $20 \mathrm{ml}$ \\
\hline $94-7-38$ & $25 \mathrm{ml}$ & $25 \mathrm{ml}$ & $25 \mathrm{ml}$ & $25 \mathrm{ml}$ \\
\hline $94-7-45$ & $25 \mathrm{ml}$ & $30 \mathrm{ml}$ & $25 \mathrm{ml}$ & $25 \mathrm{ml}$ \\
\hline Blank & $25 \mathrm{ml}$ & $20 \mathrm{ml}$ & $10 \mathrm{ml}$ & $10 \mathrm{ml}$ \\
\hline
\end{tabular}

\section{GAMMA-SPECTROMETRY RESULTS}

The gamma-spec aliquots were counted with large-volume germanium detectors for emitted photons having energies between $50-2000 \mathrm{keV}$. Each data-acquisition period was between 3 and 6 days in length. Using detector calibration parameters, gamma-ray peaks were identified with the proper energies and were corrected for detector efficiency to yield resultant photon intensities. The only radionuclides detected in the samples with this technique were ${ }^{235} \mathrm{U},{ }^{238} \mathrm{U}$, and ${ }^{237} \mathrm{~Np}$. The number of atoms thus determined in each gamma-spec sample are listed in Table 4.

It was somewhat surprising that the ${ }^{237} \mathrm{~Np}$ contamination level was so high, particularly in the Paducah samples, where the radioactivity due to decaying ${ }^{237} \mathrm{~Np}$ was comparable to that from uranium. From the radionuclide assay of the Blank specimen, no significant cross contamination among the samples was evident. The uranium measurements allow the calculation of enrichment 
values, given in the last column of Table 4. All of the Portsmouth samples are somewhat higher in ${ }^{235} \mathrm{U}$ than is natural uranium $(0.71 \%)$, while both the Paducah samples are depleted in ${ }^{235} \mathrm{U}$.

The gamma-spec results are presented here separately, instead of combined with the more precise results of the radioanalytical chemistry procedure described below, for two reasons: (1) The results were available before chemical processing was begun and were the first clear indication that procedures developed for the measurement of tracer-level actinide nuclides would need modification to accommodate the multi-milligram quantities of uranium present in the analytical samples; and (2) the data presented in Table 4 also give an indication of the limitations of the precision of radionuclide determinations via non-destructive gamma-ray spectrometry.

Table 4. Results of Gamma-Spec Analysis of Working Solution Aliquots.

$\begin{array}{lcccc}\frac{\text { Sample }}{94-7-14} & \frac{\text { U-238 atoms }}{(9.05 \pm 2.00) \mathrm{E} 17} & \frac{\text { U-235 atoms }}{(1.75 \pm 0.07) \mathrm{E} 16} & \frac{\text { Np-237 atoms }}{(1.29 \pm 0.27) \mathrm{E} 13} & \frac{\text { U-235 enrich. }}{(1.90 \pm 0.43) \%} \\ 94-7-17 & (5.39 \pm 0.79) \mathrm{E} 18 & (5.35 \pm 0.13) \mathrm{E} 16 & (3.07 \pm 0.48) \mathrm{E} 13 & (0.98 \pm 0.15) \% \\ 94-7-19 & (1.10 \pm 0.14) \mathrm{E} 19 & (3.67 \pm 0.06) \mathrm{E} 17 & \leq 9 \mathrm{E} 12 & (3.23 \pm 0.41) \% \\ 94-7-38 & (1.81 \pm 0.23) \mathrm{E} 19 & (5.50 \pm 0.18) \mathrm{E} 16 & (1.31 \pm 0.02) \mathrm{E} 15 & (0.30 \pm 0.04) \% \\ 94-7-45 & (6.92 \pm 0.80) \mathrm{E} 19 & (2.46 \pm 0.05) \mathrm{E} 17 & (2.99 \pm 0.04) \mathrm{E} 15 & (0.35 \pm 0.04) \% \\ \text { Blank } & \leq 4 \mathrm{E} 16 & \leq 5 \mathrm{E} 14 & \leq 9 \mathrm{E} 12 & -\end{array}$

\section{RADIOANALYTICAL FORENSIC PROCEDURES}

The analytical samples described in Table 3 were evaporated to dryness. Each sample was then dissolved in $9 \mathrm{M} \mathrm{HCl}$ and evaporated to dryness again to expel residual $\mathrm{HNO}_{3}$. Each sample was dissolved in $9 \mathrm{M} \mathrm{HCl}$ with $0.5 \mathrm{ml}$ of conc $\mathrm{HI}$ and evaporated to dryness, then was dissolved in $9 \mathrm{M} \mathrm{HCl}$ with $0.5 \mathrm{ml}$ of conc $\mathrm{HNO}_{3}$ and evaporated to dryness. This step was then repeated; the oxidation/ reduction cycle ensures that any added radiotracers are equilibrated with the sample.

Each sample was dissolved with $6 \mathrm{M} \mathrm{HCl}$, and $\mathrm{Fe}^{3+}$ was extracted into hexone. The hexone was then back-extracted with $6 \mathrm{M}$ HCl. These steps were repeated with fresh hexone until the organic phase became colorless, indicating little iron was left in the sample. The $6 \mathrm{M} \mathrm{HCl}$ washes were recycled to the appropriate samples.

To each fraction were added 2 drops of $10 \mathrm{mg} / \mathrm{ml} \mathrm{Fe}{ }^{3+}$ carrier, 1 drop of $10 \mathrm{mg} / \mathrm{ml}$ $\mathrm{La}^{3+}$ carrier, and 1 drop of $10 \mathrm{mg} / \mathrm{ml} \mathrm{Al}^{3+}$ carrier. The samples were evaporated to dryness and dissolved in minimum volumes of $1 \mathrm{M} \mathrm{HCl}$. The solution volumes were then doubled by the addition of conc $\mathrm{NH}_{4} \mathrm{OH}$, and the samples were digested overnight in a warm-water bath. After centrifugation, the supernatant liquids were decanted to waste, the precipitates were contacted with water, and $1 \mathrm{ml}$ of 
conc $\mathrm{NH}_{4} \mathrm{OH}$ was added to each. After digesting for an hour, the samples were centrifuged, and the supernatant liquids were decanted to waste. The hydroxide precipitates were dissolved in a minimum volume of $9 \mathrm{M} \mathrm{HCl}$, the solution volumes were doubled with addition of conc $\mathrm{HCl}$, a few drops of $8 \mathrm{M} \mathrm{HNO}_{3}$ were added to each sample, and the solutions (absent most of the original $\mathrm{Fe}, \mathrm{Ni}$ and $\mathrm{Cu}$ ) were stored until needed.

The analytical solutions were loaded onto Dowex- $1 \times 8$ anion exchange columns, 1 $\mathrm{cm}$ in diameter by $10 \mathrm{~cm}$ long, and the eluents were collected as An fractions. Subsequent column washes with $9 \mathrm{M} \mathrm{HCl}$ were combined into these An fractions. Plutonium $(\mathrm{Pu})$ was then eluted from the columns with a warm solution composed of 1 part by volume of conc HI to 12 parts of 10M HCl. Protactinium (Pa) was then eluted with a solution of composition $9 \mathrm{M}$ in $\mathrm{HCl}$ and $0.02 \mathrm{M}$ in $\mathrm{HF}$. Neptunium $(\mathrm{Np}$ ) was eluted next with a solution that was $4 \mathrm{M}$ in $\mathrm{HCl}$ and $0.1 \mathrm{M}$ in $\mathrm{HF}$. Finally, uranium (U) was eluted with $0.5 \mathrm{M} \mathrm{HCl}$. All of the fractions were evaporated to dryness prior to further processing.

$\mathrm{Np}$ fractions (from Spike Mix P samples only) were dissolved in $10 \mathrm{M} \mathrm{HCl}$ with a drop of nitric acid, heated gently, and loaded onto 4-mm-diameter Dowex-1x8 anion-exchange columns. The resin beds were washed with $10 \mathrm{M} \mathrm{HCl}$, then with $8 \mathrm{M} \mathrm{HNO}_{3}$ (until color from transition metals was gone), then with $9 \mathrm{M} \mathrm{HCl}$. Residual $\mathrm{Pu}$ was then removed by washing the column with a warm solution of 1 part conc $\mathrm{HI}$ and 12 parts $10 \mathrm{M} \mathrm{HCl}$, followed by $\mathrm{Pa}$ removal with a solution $9 \mathrm{M}$ in $\mathrm{HCl}$ and $0.02 \mathrm{M}$ in $\mathrm{HF}$. $\mathrm{Np}$ was then eluted with a solution $4 \mathrm{M}$ in $\mathrm{HCl}$ and $0.1 \mathrm{M}$ in $\mathrm{HF}$. The $\mathrm{Np}$ fractions were evaporated to dryness, dissolved in $8 \mathrm{M} \mathrm{HNO}_{3}$, and loaded on 2.5-mm-diameter Dowex- $1 \times 8$ columns, which were washed sequentially with solutions of $8 \mathrm{M} \mathrm{HNO}_{3}, 9 \mathrm{M} \mathrm{HCl}$, and warm 1-to-12 conc $\mathrm{HI} / 10 \mathrm{M} \mathrm{HCl}$. Once again, $\mathrm{Np}$ was eluted with a solution $4 \mathrm{M}$ in $\mathrm{HCl}$ and $0.1 \mathrm{M}$ in $\mathrm{HF}$, and the $\mathrm{Np}$ fractions were evaporated to dryness. The $\mathrm{Np}$ fractions were dissolved in $8 \mathrm{M}$ $\mathrm{HNO}_{3}$ and loaded onto 2.5-mm-diameter Dowex-1x8 columns, which were washed sequentially with $8 \mathrm{M} \mathrm{HNO}_{3}$ and $9 \mathrm{M} \mathrm{HCl}$. $\mathrm{Np}$ was eluted with $0.5 \mathrm{M} \mathrm{HCl}$, and the solutions were evaporated to dryness.

$\mathrm{Pa}$ fractions (from Spike Mix N samples only) were dissolved in $8 \mathrm{M} \mathrm{HNO}_{3}$ and were loaded onto 6-mm-diameter Dowex-1x8 anion-exchange columns. The resin beds were washed with $8 \mathrm{M} \mathrm{HNO}_{3}$ (until color from transition metals was gone), then with $9 \mathrm{M} \mathrm{HCl}$. $\mathrm{Pa}$ was eluted with a solution $9 \mathrm{M}$ in $\mathrm{HCl}$ and $0.02 \mathrm{M}$ in $\mathrm{HF}$. The $\mathrm{Pa}$ fractions were evaporated to dryness, dissolved in $8 \mathrm{M} \mathrm{HNO}_{3}$, and loaded onto 2.5-mm-diameter Dowex-1x8 columns, which were then sequentially washed with $8 \mathrm{M} \mathrm{HNO}_{3}, 9 \mathrm{M} \mathrm{HCl}$, and warm 1-to-12 conc HI/10M HCl. Pa was then eluted with $9 \mathrm{M} \mathrm{HCl} / 0.02 \mathrm{M} \mathrm{HF}$, after which the fractions were evaporated to dryness.

U fractions (from Spike Mix P and Unspiked samples only) were dissolved in 8M $\mathrm{HNO}_{3}$ and were loaded onto 4-mm-diameter Dowex-1x8 anion-exchange columns. The resin beds were washed with a small volume of $8 \mathrm{M} \mathrm{HNO}_{3}$, then with $9 \mathrm{M} \mathrm{HCl}$. 
Residual $\mathrm{Pu}$ was removed by washing the column with a warm solution of 1 part conc $\mathrm{HI}$ and 12 parts $10 \mathrm{M} \mathrm{HCl}$, followed by residual $\mathrm{Pa}$ and $\mathrm{Np}$ removal with a solution $4 \mathrm{M}$ in $\mathrm{HCl}$ and $0.1 \mathrm{M}$ in $\mathrm{HF}$. U fractions were eluted with $0.5 \mathrm{M} \mathrm{HCl}$, and were then evaporated to dryness. The $U$ fractions were dissolved in $8 \mathrm{M} \mathrm{HNO}_{3}$ and were loaded onto 4-mm-diameter Dowex-1x8 columns, which were then sequentially washed with $8 \mathrm{M} \mathrm{HNO}_{3}, 9 \mathrm{M} \mathrm{HCl}$, and $4 \mathrm{M} \mathrm{HCl} / 0.1 \mathrm{M} \mathrm{HF}$, after which the $U$ fractions were eluted with $0.5 \mathrm{M} \mathrm{HCl}$ and evaporated to dryness. U fractions were then dissolved in $8 \mathrm{M} \mathrm{HNO}_{3}$ and were loaded onto 4-mm-diameter Dowex-1x8 columns, which were then washed with $8 \mathrm{M} \mathrm{HNO}_{3}$ and with $9 \mathrm{M} \mathrm{HCl}$. Final U fractions were then eluted with $0.5 \mathrm{M} \mathrm{HCl}$ and evaporated to dryness.

$\mathrm{Pu}$ fractions (from all analytical samples) were dissolved in $8 \mathrm{M} \mathrm{HNO}_{3}$. To each fraction was added a drop of saturated $\mathrm{NH}_{4} \mathrm{NO}_{2}$; the samples were heated briefly, then loaded onto 4-mm-diameter Dowex- $1 \times 8$ anion-exchange columns. The resin beds were washed with $8 \mathrm{M} \mathrm{HNO}_{3}$, then with $9 \mathrm{M} \mathrm{HCl}$, after which $\mathrm{Pu}$ fractions were eluted with a warm solution of 1 part conc $\mathrm{HI}$ and 12 parts $10 \mathrm{M} \mathrm{HCl}$. The $\mathrm{Pu}$ fractions were evaporated to dryness, dissolved in warm $8 \mathrm{M} \mathrm{HNO}_{3}$ with a drop of saturated $\mathrm{NH}_{4} \mathrm{NO}_{2}$, and the previous ion-exchange step was repeated using a 2.5mm-diameter Dowex- $1 \times 8$ column. The resultant $\mathrm{Pu}$ fractions were evaporated to dryness, dissolved in warm $8 \mathrm{M} \mathrm{HNO}_{3}\left(\mathrm{NH}_{4} \mathrm{NO}_{2}\right)$, and loaded onto 2.5-mmdiameter Dowex-1x8 columns, which were washed sequentially with copious $8 \mathrm{M}$ $\mathrm{HNO}_{3}$ (final $\mathrm{U}$ decontamination) and $9 \mathrm{M} \mathrm{HCl}$. Final $\mathrm{Pu}$ fractions were then eluted with $0.5 \mathrm{M} \mathrm{HCl}$ and evaporated to dryness.

An fractions (from all analytical samples) were dissolved in $8 \mathrm{M} \mathrm{HNO}_{3}$. To each fraction was added a drop of saturated $\mathrm{NH}_{4} \mathrm{NO}_{2}$; the samples were heated briefly, then loaded onto 6-mm-diameter Dowex-1x8 anion-exchange columns. The resin beds were washed with $8 \mathrm{M} \mathrm{HNO}_{3}$; the load and wash solutions were collected as An fractions (containing Am, Ac, and $\mathrm{Ra}$ ). Thorium (Th) fractions were then eluted from the columns with $9 \mathrm{M} \mathrm{HCl}$ and evaporated to dryness (see below). An fractions were evaporated to dryness several times with addition of $9 \mathrm{M} \mathrm{HCl}$ (to remove nitrate ion), after which they were dissolved in water and loaded onto 6mm-diameter Dowex-50x4 cation-exchange columns. It often took several water additions followed by column loadings to completely dissolve the samples. The resin beds were then washed with copious $0.5 \mathrm{M} \mathrm{HCl}$ and then with $1 \mathrm{M} \mathrm{HCl}$, after which An fractions were eluted with $9 \mathrm{M}$ HCl. The An fractions were evaporated to dryness, dissolved in water, and loaded onto 4-mm-diameter Dowex-50x4 columns, which were washed sequentially with $0.5 \mathrm{M} \mathrm{HCl}, 1 \mathrm{M} \mathrm{HCl}$, and $2 \mathrm{M} \mathrm{HCl}$. At the first indication of ${ }^{241} \mathrm{Am}$ alpha activity in the $2 \mathrm{M} \mathrm{HCl}$ eluents, An fractions were eluted with $6 \mathrm{M}$ HCl. After the An fractions were evaporated to dryness, the last step was repeated with 2.5-mm-diameter Dowex-50x4 columns. The resultant An fractions were evaporated to dryness. An fractions derived from the Spike Mix $\mathrm{P}$ samples were further processed as follows: The fractions were dissolved in saturated (nominally $13 \mathrm{M}$ ) $\mathrm{HCl}$ and loaded onto 2.5-mm-diameter AG MP-50 cation-exchange columns. Americium ( $\mathrm{Am})$, radium (Ra), and 
lanthanum/actinium (Ac) fractions were sequentially eluted from the columns with saturated $\mathrm{HCl}$, and were evaporated to dryness.

Th fractions (from An fractions derived from Spike Mix P and Unspiked samples) were dissolved in $8 \mathrm{M} \mathrm{HNO} \mathrm{HNO}_{3}$. To each sample was added a drop of saturated $\mathrm{NH}_{4} \mathrm{NO}_{2}$; the samples were heated briefly and then loaded onto 4-mm-diameter Dowex-1x8 anion-exchange columns. After column washes with $8 \mathrm{M} \mathrm{HNO}_{3}$, Th fractions were eluted with $9 \mathrm{M} \mathrm{HCl}$. The Th fractions were evaporated to dryness, dissolved in $8 \mathrm{M} \mathrm{HNO}_{3}$, and loaded onto 2.5 -mm-diameter Dowex-1x8 columns, which were then washed with $8 \mathrm{M} \mathrm{HNO}_{3}$. Th fractions were eluted with $9 \mathrm{M} \mathrm{HCl}$ and evaporated to dryness. The previous ion-exchange step was repeated, and the final Th fractions were evaporated to dryness.

Ra fractions from samples 94-7-38 and 94-7-45 contained ${ }^{226} \mathrm{Ra}$, as determined by alpha spectroscopy (see below). Unfortunately, the chemical yield as determined from short-lived ${ }^{224} \mathrm{Ra}$ in the Spike Mix $\mathrm{P}$ samples was not valid; early precipitation steps, that may have had poor efficiencies for $\mathrm{Ra}$ resulted in intermediate samples containing high yields of the ${ }^{228} \mathrm{Th}$ precursor nuclide, which would have caused ${ }^{224} \mathrm{Ra}$ to grow back into the samples. For the two samples with indications of $\mathrm{Ra}$, special analytical samples were constructed from $15 \mathrm{ml}$ of working solution and three times the standard P Mix aliquot. After a single oxidation/reduction cycle and several hexone extractions (described above), the samples were evaporated to dryness, dissolved in $9 \mathrm{M} \mathrm{HCl}$, and loaded on 8mm-diameter Dowex-1x8 anion exchange columns, which were then washed with more $9 \mathrm{M} \mathrm{HCl}$. The load and wash solutions were collected as $\mathrm{Ra}$ fractions, evaporated to dryness several times with the addition of $\mathrm{HNO}_{3}$, and were then dissolved in $8 \mathrm{M} \mathrm{HNO}_{3}$. These solutions were loaded onto 4-mm-diameter Dowex1x8 columns, which were then washed with more $8 \mathrm{M} \mathrm{HNO}_{3}$ (this is the Th/Ra separation time). The load and wash solutions were collected as the Ra fractions, and evaporated to dryness several times with the addition of $6 \mathrm{M} \mathrm{HCl}$. The Ra fractions were then treated to the same cation-exchange procedure outlined above for the An fractions, including the AG MP-50 step. Final Ra fractions were evaporated to dryness.

Final $\mathrm{Ra}, \mathrm{Ac}, \mathrm{Th}, \mathrm{Pa}, \mathrm{Np}$, and Am samples were dissolved in minimum volumes of $6 \mathrm{M} \mathrm{HCl}$ and transferred to tungsten filaments where they were re-evaporated. Counting samples were prepared by volatilizing the samples onto 1-inch diameter platinum disks through the rapid heating of the filaments. $U$ fractions were subdivided into several samples of different strengths; some of these were volatilized onto platinum, while others were subjected to isotopic analysis by inductively-coupled-plasma mass spectrometry (ICP-MS). $\mathrm{Pu}$ fractions from Spike Mix $\mathrm{P}$ and Spike Mix $\mathrm{N}$ samples were volatilized onto platinum, as were all Unspiked fractions except those from samples 94-7-38 and 94-7-45, which were analyzed for isotopic composition by thermal-ionization mass spectrometry (TIMS). 
$\mathrm{Np}$ and $\mathrm{Pa}$ samples were mounted in standard-geometry gamma-spec holders and were counted close to the faces of large-volume germanium photon detectors; gamma-ray intensities were used to measure the activities of the ${ }^{239} \mathrm{~Np}$ and ${ }^{233} \mathrm{~Pa}$ chemical-yield indicators. Gross alpha-decay rates of these samples were measured with calibrated 2-pi gas-proportional counters in order to complete the link to chemical yields. All Pt-backed samples were pulse-height analyzed for alpha particle emission with surface-barrier or Frisch-grid gas-filled detectors.

In total, more than 130 samples were generated and counted in the course of these radioanalytical analyses.

\section{RADIOANALYTICAL RESULTS}

Results of the analyses of the six working solutions are given in Table 5, scaled to the masses of the original samples. These data are derived from a combination of alpha-particle, gamma-ray, and mass spectrometry analyses. Data are given in atoms, except for ${ }^{239} \mathrm{Pu}$ and ${ }^{240} \mathrm{Pu}$ for those samples where $\mathrm{Pu}$ fractions were not subjected to mass-spectrometric analysis. Since ${ }^{239} \mathrm{Pu}$ and ${ }^{240} \mathrm{Pu}$ are not resolvable with alpha spectroscopy (due to their similar alpha-decay energies), the sum of their activities (in disintegrations/minute) is given in the Table. Assessments of ${ }^{239} \mathrm{Pu}$ content are derived from ${ }^{240} \mathrm{Pu} /{ }^{239} \mathrm{Pu}$ mass ratios estimated from ${ }^{238} \mathrm{Pu} /\left({ }^{239} \mathrm{Pu}+{ }^{240} \mathrm{Pu}\right)$ activity ratios (see below). Values listed for ${ }^{233} \mathrm{U}$ are calculated from the ${ }^{234} \mathrm{U}$ content and the relative amounts of their decay daughters $\left({ }^{229} \mathrm{Th}\right.$ and ${ }^{230} \mathrm{Th}$, respectively); as will be seen below, this may not be an unambiguous calculation.

The distribution of uranium isotopes in each sample is given in Table 6 in the form of atom ratios to ${ }^{238} \mathrm{U}$ content. These are substantially the same data given in Table 5, but do not include the propagated error on chemical yield.

Observables in the plutonium fractions are given in Table 7 . The ${ }^{238} \mathrm{Pu} /\left({ }^{239} \mathrm{Pu}+{ }^{240} \mathrm{Pu}\right)$ activity ratios were obtained from alpha spectroscopy, while the atom ratios are the results of thermal-ionization mass spectrometry. The data for the higher-mass $\mathrm{Pu}$ isotopes in sample 94-7-38 were compromised by a contamination in the instrument; even the ${ }^{240} \mathrm{Pu} /{ }^{239} \mathrm{Pu}$ ratio for that sample should be treated with suspicion. 
Table 5. Results of the Analysis of the Heavy-Element Contents of Selected PUBLIC Samples. Data are total atoms in each sample, decay corrected to day 260,1994 . Also given are disintegrations per minute of the sum of ${ }^{239} \mathrm{Pu}$ and ${ }^{240} \mathrm{Pu}$ in each sample. (Continued on next page.)

$\begin{array}{llll}\frac{\text { Nuclide }}{243} \mathrm{Am} & \underline{94-7-14} & \underline{94-7-17} & \underline{94-7-19} \\ 241 \mathrm{Am} & (5.22 \pm 1.43) \mathrm{E} 9 & (1.60 \pm 0.20) \mathrm{E} 9 & (9.14 \pm 3.28) \mathrm{E} 8 \\ { }^{242} \mathrm{Pu} & \leq 1.6 \mathrm{E} 10 & \leq 8.6 \mathrm{E} 9 & \leq 2.0 \mathrm{E} 10 \\ 241 \mathrm{Pu} & & & \\ 240 \mathrm{Pu} & & \sim 2 \mathrm{E} 11 & \sim 1 \mathrm{E} 11 \\ 239 \mathrm{Pu} & \sim 9 \mathrm{E} 10 & (1.57 \pm 0.21) \mathrm{E} 7 & (4.58 \pm 0.77) \mathrm{E} 7 \\ 238 \mathrm{Pu} & (4.43 \pm 0.47) \mathrm{E} 7 & \leq 2.5 \mathrm{E} 5 & \leq 1.4 \mathrm{E} 5 \\ 236 \mathrm{Pu} & \leq 4.1 \mathrm{E} 5 & (8.46 \pm 0.50) \mathrm{E} 13 & (3.57 \pm 1.93) \mathrm{E} 13 \\ { }^{237} \mathrm{~Np} & (2.96 \pm 0.29) \mathrm{E} 13 & (1.63 \pm 0.05) \mathrm{E} 19 & (4.23 \pm 0.07) \mathrm{E} 19 \\ { }^{238 \mathrm{U}} & (3.23 \pm 0.13) \mathrm{E} 18 & (9.54 \pm 0.67) \mathrm{E} 14 & (1.75 \pm 0.08) \mathrm{E} 15 \\ { }^{236 \mathrm{U}} & (2.24 \pm 0.14) \mathrm{E} 14 & (1.80 \pm 0.06) \mathrm{E} 17 & (1.66 \pm 0.03) \mathrm{E} 18 \\ 235 \mathrm{U} & (5.61 \pm 0.23) \mathrm{E} 16 & (1.03 \pm 0.03) \mathrm{E} 15 & (1.71 \pm 0.03) \mathrm{E} 16 \\ { }^{234} \mathrm{U} & (3.36 \pm 0.14) \mathrm{E} 14 & (1.035 & \leq 2.3 \mathrm{E} 12 \\ 233 \mathrm{U} & \leq 1.3 \mathrm{E} 11 & \leq 1.5 \mathrm{E} 11 & (5.86 \pm 0.40) \mathrm{E} 8 \\ 232 \mathrm{U} & \leq 1.5 \mathrm{E} 7 & (2.07 \pm 1.79) \mathrm{E} 7 & (5.27 \pm 0.31) \mathrm{E} 11 \\ { }^{231} \mathrm{~Pa} & \leq 6.3 \mathrm{E} 10 & \leq 1.3 \mathrm{E} 11 & (2.08 \pm 1.29) \mathrm{E} 15 \\ 232 \mathrm{Th} & (3.59 \pm 2.17) \mathrm{E} 15 & (3.77 \pm 2.09) \mathrm{E} 15 & (5.33 \pm 0.28) \mathrm{E} 12 \\ 230 \mathrm{Th} & (1.54 \pm 0.09) \mathrm{E} 12 & (7.14 \pm 0.38) \mathrm{E} 12 & (2.0 \mathrm{E} 9 \\ 229 \mathrm{Th} & \leq 9.0 \mathrm{E} 8 & \leq 1.4 \mathrm{E} 9 & \leq 12 \\ 227 \mathrm{Ac} & (4.05 \pm 2.08) \mathrm{E} 7 & \leq 2.5 \mathrm{E} 7 & \leq 2.9 \mathrm{E} 7 \\ 226 \mathrm{Ra} & & & \\ \text { activity } & & & (8.40 \pm 0.26) \\ { }^{239} \mathrm{Pu}+{ }^{240} \mathrm{Pu} & (7.10 \pm 0.20) & (13.65 \pm 0.30) & \end{array}$


Table 5. (continued)

$\begin{array}{llll}\frac{\text { Nuclide }}{243} \mathrm{Am} & \frac{94-7-38}{\leq 1.6 \mathrm{E} 9} & \frac{94-7-45}{\leq 5.8 \mathrm{E} 9} & \underline{\text { Blank }} \\ 241 \mathrm{Am} & (3.89 \pm 0.06) \mathrm{E} 10 & (1.23 \pm 0.02) \mathrm{E} 11 & \leq 7.4 \mathrm{E} 8 \\ 242 \mathrm{Pu} & \leq 1.5 \mathrm{E} 11 & (1.06 \pm 0.11) \mathrm{E} 10 & \\ 241 \mathrm{Pu} & & (3.79 \pm 0.15) \mathrm{E} 10 & \\ 240 \mathrm{Pu} & (5.59 \pm 0.19) \mathrm{E} 11 & (1.81 \pm 0.02) \mathrm{E} 12 & \\ 239 \mathrm{Pu} & (8.12 \pm 0.10) \mathrm{E} 12 & (2.79 \pm 0.03) \mathrm{E} 13 & \leq 6.0 \mathrm{E} 9 \\ 238 \mathrm{Pu} & (9.70 \pm 0.28) \mathrm{E} 8 & (2.36 \pm 0.06) \mathrm{E} 9 & \\ 236 \mathrm{Pu} & \leq 3.7 \mathrm{E} 5 & \leq 8.3 \mathrm{E} 5 & \\ 237 \mathrm{~Np} & (7.81 \pm 0.08) \mathrm{E} 15 & (2.56 \pm 0.02) \mathrm{E} 16 & \leq 6.0 \mathrm{E} 11 \\ 238 \mathrm{U} & (9.70 \pm 0.33) \mathrm{E} 19 & (5.25 \pm 0.15) \mathrm{E} 20 & \leq 8.0 \mathrm{E} 15 \\ 236 \mathrm{U} & (3.85 \pm 0.17) \mathrm{E} 15 & (2.08 \pm 0.09) \mathrm{E} 16 & \\ 235 \mathrm{U} & (3.22 \pm 0.11) \mathrm{E} 17 & (2.03 \pm 0.06) \mathrm{E} 18 & \\ 234 \mathrm{U} & (1.90 \pm 0.07) \mathrm{E} 15 & (1.24 \pm 0.04) \mathrm{E} 16 & \leq 4.4 \mathrm{E} 10 \\ 233 \mathrm{U} & \leq 1.5 \mathrm{E} 10 & (1.77 \pm 0.73) \mathrm{E} 11 & \\ 232 \mathrm{U} & \leq 9.6 \mathrm{E} 7 & \leq 2.5 \mathrm{E} 8 & \\ { }^{231} \mathrm{~Pa} & (2.82 \pm 0.26) \mathrm{E} 11 & (8.53 \pm 0.58) \mathrm{E} 11 & \leq 5.0 \mathrm{E} 10 \\ 232 \mathrm{Th} & (1.49 \pm 0.13) \mathrm{E} 17 & (3.28 \pm 0.26) \mathrm{E} 17 & \leq 3.0 \mathrm{E} 15 \\ 230 \mathrm{Th} & (1.29 \pm 0.07) \mathrm{E} 14 & (5.15 \pm 0.27) \mathrm{E} 14 & \leq 3.0 \mathrm{E} 10 \\ 229 \mathrm{Th} & \leq 1.3 \mathrm{E} 9 & (1.16 \pm 0.44) \mathrm{E} 10 & \\ 227 \mathrm{Ac} & \leq 3.5 \mathrm{E} 7 & (1.24 \pm 0.46) \mathrm{E} 8 & \leq 4.0 \mathrm{E} 7 \\ 226 \mathrm{Ra} & (1.26 \pm 0.15) \mathrm{E} 10 & (3.23 \pm 1.13) \mathrm{E} 10 & \\ & & & \\ \text { activity } & & & \\ { }^{239} \mathrm{Pu}+240 \mathrm{Pu} & (556.3 \pm 5.5) & (1886 \pm 16) & \leq 0.30 \\ & & & \end{array}$


Table 6. The Uranium Isotopics of PUBLIC Samples, Atom Ratios. Natural uranium values are included for comparison.

$\begin{array}{llll}\frac{\text { Ratio }}{{ }^{232} \mathrm{U} / 238 \mathrm{U}} & \frac{94-7-14}{\leq 5 \mathrm{E}-12} & \frac{94-7-17}{(1.3 \pm 1.1) \mathrm{E}-12} & \frac{94-7-19}{(1.38 \pm 0.10) \mathrm{E}-11} \\ { }^{233} \mathrm{U} / 238 \mathrm{U} & \leq 4 \mathrm{E}-8 & \leq 9 \mathrm{E}-9 & \leq 6 \mathrm{E}-8 \\ { }^{234} \mathrm{U} /{ }^{238} \mathrm{U} & (1.040 \pm 0.011) \mathrm{E}-4 & (6.30 \pm 0.06) \mathrm{E}-5 & (4.034 \pm 0.020) \mathrm{E}-4 \\ { }^{235} \mathrm{U} / 238 \mathrm{U} & (1.738 \pm 0.013) \mathrm{E}-2 & (1.108 \pm 0.009) \mathrm{E}-2 & (3.927 \pm 0.016) \mathrm{E}-2 \\ { }^{236} \mathrm{U} / 238 \mathrm{U} & (6.92 \pm 0.29) \mathrm{E}-5 & (5.86 \pm 0.37) \mathrm{E}-5 & (4.14 \pm 0.04) \mathrm{E}-5\end{array}$

Table 6. (continued)

$\begin{array}{llll}\frac{\text { Ratio }}{232 \mathrm{U} / 238} \mathrm{U} & \frac{94-7-38}{\leq 1 \mathrm{E}-12} & \frac{947-45}{\leq 5 \mathrm{E}-13} & \text { natural } \\ { }^{233} \mathrm{U} /{ }^{238} \mathrm{U} & \leq 2 \mathrm{E}-10 & (3.4 \pm 1.4) \mathrm{E}-10 & 0 . \\ { }^{234} \mathrm{U} / 238 \mathrm{U} & (1.960 \pm 0.013) \mathrm{E}-5 & (2.358 \pm 0.017) \mathrm{E}-5 & 5.47 \mathrm{E}-5 \\ { }^{235} \mathrm{U}^{238} \mathrm{U} & (3.320 \pm 0.021) \mathrm{E}-3 & (3.873 \pm 0.027) \mathrm{E}-3 & 7.25 \mathrm{E}-3 \\ { }^{236} \mathrm{U} / 238 \mathrm{U} & (3.97 \pm 0.12) \mathrm{E}-5 & (3.96 \pm 0.15) \mathrm{E}-5 & 0 .\end{array}$

Table 7. Observables in PUBLIC Samples, Plutonium Fractions.

\begin{tabular}{|c|c|c|c|c|}
\hline & Activity & \multicolumn{3}{|c|}{ Atom ratios } \\
\hline Sample & ${ }^{238} \mathrm{Pu} /\left({ }^{239} \mathrm{Pu}+{ }^{240} \mathrm{Pu}\right)$ & ${ }^{240} \mathrm{Pu} / 239 \mathrm{Pu}$ & ${ }^{241} \mathrm{Pu} /{ }^{239} \mathrm{Pu}$ & ${ }^{242} \mathrm{Pu} /{ }^{239} \mathrm{Pu}$ \\
\hline$-7-$ & $0.0936 \pm 0.0089$ & & & \\
\hline 7 & $0.0173 \pm 0.0023$ & & & \\
\hline$-7-1$ & $0.0816 \pm 0.0131$ & & & \\
\hline$-7-3$ & $0.0262 \pm 0.0007$ & $0.069 \pm 0.002$ & & \\
\hline$-7-4$ & $0.0188 \pm 0.0004$ & $0.0648 \pm 0.0001$ & $0.00136 \pm 0.0005$ & $0.00038 \pm 0.00004$ \\
\hline
\end{tabular}

Results for the radioanalytic Blank are consistent with a negligible radionuclide content, giving no evidence for significant cross-contamination among the samples. The data in the last column of Table 5 also give a feeling for the sensitivity of technique, of potential use in the planning for future site inspections. 


\section{DISCUSSION AND CONCLUSIONS}

The basic assumption underlying all the data interpretation that follows is that, unless otherwise indicated, the radionuclide content of a given sample is characteristic of a specific location in the enrichment cascade, and that there was a single release time associated with that sample. Contributions from multiple releases of material at different cascade process times would compromise many of the following conclusions.

Information about operations at the Paducah and Portsmouth plants is available in the unclassified literature (e.g. "Recent Developments in Uranium Enrichment", J. R. Merriman and M. Benedict, eds., AIChE Symposium Series 221, New York, 1982; and "Uranium Enrichment", S. Villani, ed., SpringerVerlag, Berlin, 1979). This is the starting point of the ensuing forensic analysis: The main function at both plants is the enrichment of uranium by means of gaseous diffusion of warm $\mathrm{UF}_{6}$; however, other enrichment techniques have been explored (e.g. gas-centrifuge), and might have contributed to the isotopic content of specific samples, but not significantly to the general level of contamination at these sites. Operations at both plants started in the mid-1950's and continue to the present. During much of this time, the Paducah plant has produced uranium with a low enrichment of ${ }^{235} U$ (1-5\%), some of which has been used as feed stock at the Portsmouth plant, which makes several different products at ${ }^{235} \mathrm{U}$ enrichments of up to $97 \%$.

The last statement is confirmed by the data in Table 6: It is much more likely that feed or tails materials would be represented in the site-collection samples than would be product materials, both because of their relative masses and their relative values. The Paducah samples (94-7-38 and 94-7-45) are distinctly depleted in ${ }^{235} \mathrm{U}$ relative to natural uranium $\left({ }^{235} \mathrm{U} /{ }^{238} \mathrm{U}_{\text {nat }}=7.25 \times 10^{-3}\right)$, but those from Portsmouth are all distinctly enriched. The fact that each of the five samples represents a different ${ }^{235} \mathrm{U}$ enrichment is confirmation that these are plants that are actively changing the isotopics of uranium and not just utilizing materials modified at other facilities.

Most of the diffusion barrier in both plants was replaced between 1975 and 1983 in a "Cascade Improvement Program (CIP)". Because of the enormous volume of contaminated material handled during the CIP, it seems likely that most of the site contamination, particularly in sheltered or out-of-the-way places, dates from that time.

An examination of the data in Tables 5 and 6 shows that there is a significant amount of ${ }^{236} \mathrm{U}$ present in the samples. The mass-236 isotope is not a component in natural uranium, arising only in the interaction of neutrons with ${ }^{235} \mathrm{U}$. This proves that at least some of the cascade feed material had been irradiated in a reactor, and that the plutonium and neptunium in the samples probably came into the plants as contaminants in the uranium, rather than as unrelated entities. Furthermore, the mass-240 content of the plutonium in the Paducah 
samples (Table 7) is not what one would expect of material that had been used in high-burn-up power applications, but is characteristic of the enrichments found in standard weapons-grade materials. Therefore, even though we did not find any direct evidence of highly-enriched uranium, the sample analyses clearly indicate that the plants have some tie to the weapons complex.

The ORIGEN2 code (A. G. Croff, Nucl.Tech. 62, 335 (1983); ORNL RISC Computer Code Collection, CCC-371, rev. 1991) was used to understand the isotopic compositions of the PUBLIC samples. ORIGEN2 calculates the nuclide content of nuclear fuels at specified burn-up intervals for several types of reactor. The calculated correlations between the mass ratio ${ }^{240} \mathrm{Pu} /{ }^{239} \mathrm{Pu}$ and the activity ratio ${ }^{238} \mathrm{Pu} /\left({ }^{239} \mathrm{Pu}+{ }^{240} \mathrm{Pu}\right)$ for three standard reactor types and an external target (Thermal) are given in figure 1 . Reactors that are unlikely to have contributed to weapons production in the 1960's (e.g. mixed-fuel, or liquid-metal-cooled) have not been considered. A reactor power level of $37.5 \mathrm{MW}$ thermal was assumed for the calculations. The measured data from the Paducah samples fall in between the curves given for CANDU and Boiling Water Reactors. ${ }^{238} \mathrm{Pu}$ is a fairly short-lived nuclide $\left(t_{1 / 2}=88\right.$ years); since the samples are probably at least 15 years old (midpoint of the CIP), allowance for radioactive decay occurring since the material was discharged from a reactor would lead to a corrected value for ${ }^{238} \mathrm{Pu} /\left({ }^{239} \mathrm{Pu}+{ }^{240} \mathrm{Pu}\right)$ significantly closer to the BWR curve. Moreover, the mass diffusion principle works on the $\mathrm{Pu}$ isotopes in $\mathrm{PuF}_{6}$ as readily as it does on the $\mathrm{U}$ isotopes in $\mathrm{UF}_{6}$. The Paducah samples consisted of plant tails materials, depleted in low-mass isotopes; consequently, a correction for the action of the diffusion process would also lead to Pu data closer to the BWR curve (see Figure 2).

Feed material to the Paducah plant was probably not significantly enriched (or depleted) in ${ }^{235} \mathrm{U}$. If the $\mathrm{Pu}$ component of the plant feed had been produced in a reactor with enriched fuel, a much higher ${ }^{240} \mathrm{Pu} /{ }^{239} \mathrm{Pu}$ value would have resulted from an irradiation that would have burned the ${ }^{235} \mathrm{U}$ content to near-natural levels. This implies that the production of weapons-grade $\mathrm{Pu}$ in the U.S. took place in reactors using uranium fuel of near-natural composition. However, the observables in the Paducah $\mathrm{Pu}$ samples do not match the ORIGEN2 calculations for either of the natural-uranium-fueled standard reactor types, particularly after making the above-mentioned corrections. It would be naive to conclude that $\mathrm{Pu}$ production occurred in BW or PW Reactors with lower fuel enrichments though; an ORIGEN2 calculation for a hypothetical (unrealistic) natural-fuel BWR resulted in the curve given in figure 2, compared with the same calculation depicted in figure 1 for a $3.2 \%$-enrichment ${ }^{235} \mathrm{U}$ BWR. Some of the difference between the calculations results from the fact that much of the production of ${ }^{238} \mathrm{Pu}$ is from capture of a neutron by ${ }^{237} \mathrm{~Np}$; at medium-to-long irradiation times, ${ }^{237} \mathrm{~Np}$ arises largely from sequential capture of two neutrons by ${ }^{235} \mathrm{U}$ followed by beta decay of 6.7 -day ${ }^{237} \mathrm{U}$. An enrichment in the ${ }^{235} \mathrm{U}$ content of the starting material thereby results in an increase in production of ${ }^{238} \mathrm{Pu}$. 
Also shown in Figure 2 are measured Paducah plutonium observables (given as circular data points). The result of correcting the $\mathrm{Pu}$ data for a 20 -year decay period and an enrichment (or depletion) of $33 \%$ of that defined by the ${ }^{235} \mathrm{U}$-content of the uranium component of the samples (since the mass difference among the $\mathrm{Pu}$ isotopes is only \pm 1 unit, while it is -3 in the uranium) is denoted by the triangular points. While there is seeming agreement between the original data and the "natural-uranium BWR" curve, modified Pu isotopics very closely match those expected from an enriched-fuel BWR after realistic corrections are made for decay and the effects of mass separation.

There is thus an apparent conflict in that a natural-fuel reactor is required by the comparison of the analytical data with the literature, but the only reactor types in the ORIGEN2 data library that fit the corrected measurements require enriched fuel. However, another path to ${ }^{238} \mathrm{Pu}$ is through the interaction of high-energy neutrons with ${ }^{239} \mathrm{Pu}$ via the ${ }^{239} \mathrm{Pu}(\mathrm{n}, 2 \mathrm{n})$ reaction. Production of the $\mathrm{Pu}$ isotopic mix in the Paducah samples from natural uranium requires a harder neutron spectrum than that generated by the reactors in the calculations, implying a less efficient (higher Z) moderator than either light or heavy water. This means that U.S. weapons-grade $\mathrm{Pu}$ production takes place in graphite-moderated reactors. Unfortunately, the ORIGEN2 libraries available at LLNL do not contain a graphite-moderated "Production Reactor" data set. Nevertheless, since the production of most of the uranium and plutonium isotopes are through neutroncapture reactions that are relatively spectrum insensitive, it seems likely that $\mathrm{Pu}$ and $U$ production in the hypothetical "natural-uranium BWR" would closely approximate that resulting in the cascade feed material.

The isotopic composition of plutonium as a function of burn-up in a "naturaluranium $B W R$ " is given in figure 3 , along with the production of ${ }^{239} \mathrm{Pu}$ relative to the unburned ${ }^{238} \mathrm{U}$ remaining in the fuel. The value of ${ }^{239} \mathrm{Pu}$ used in the calculation of these ratios is the sum of the number of atoms of ${ }^{239} \mathrm{U},{ }^{239} \mathrm{~Np}$, and ${ }^{239} \mathrm{Pu}$ given in the code output at the appropriate irradiation length. Again, a power level of 37.5 MW thermal is assumed in the calculation. The isotopic ratios obtained from sample 94-7-45 (Table 7) are plotted as circular points at an irradiation time of 33 days (1250 MW-days), which is defined by the ${ }^{240} \mathrm{Pu} /{ }^{239} \mathrm{Pu}$ value. The value of ${ }^{242} \mathrm{Pu} /{ }^{239} \mathrm{Pu}$ for the sample falls very close to the appropriate curve. ${ }^{241} \mathrm{Pu}$ is a short-lived nuclide $\left(t_{1 / 2}=14.4\right.$ years $)$; a decay correction of 41 years is required to adjust the observed data to the 241/239 curve. This decay time (i.e. average time of reactor discharge in 1953) is not inconsistent with the time since last chemical separation calculated from the ${ }^{241} \mathrm{Am}$ content of the sample (see below).

Correction of the $\mathrm{Pu}$ isotope ratios for the action of the cascade, assuming a linear enrichment with mass number as estimated from the ${ }^{235} \mathrm{U} / 238 \mathrm{U}$ value for sample 94-7-45 (Table 6) results in the data plotted as triangular points at an irradiation time of 28.5 days (1070 MW-days) in figure 3. The fit of the corrected value of ${ }^{242} \mathrm{Pu} /{ }^{239} \mathrm{Pu}$ to the calculated curve becomes better. The decay correction required 
to make the adjusted value of ${ }^{241} \mathrm{Pu} /{ }^{239} \mathrm{Pu}$ fit the calculated curve increases slightly, to 42 years. The assumption of a linear relationship between enrichment and isotope mass is probably reasonable for small enrichments, such as that resulting in sample 94-7-45; for larger enrichments it is no longer appropriate (see below).

Comparison of the plutonium data from the Paducah sample with the curves given in figure 3 indicates that the accuracy of the calculation for the production of plutonium isotopes in a pre-cascade reactor irradiation is good. Therefore, it can be assumed that the change of uranium isotope ratios with irradiation time is also well reproduced by the code. Uranium isotope ratios from the same ORIGEN2 calculation are given in Figure 4, along with the production of ${ }^{237} \mathrm{~Np}$ (including 6.7-day ${ }^{237} \mathrm{U}$ ) relative to residual ${ }^{238} \mathrm{U}$.

From Figure 3, the discharged reactor fuel that contributed to the Paducah feed stock could be expected to have a ${ }^{239} \mathrm{Pu} /{ }^{238} \mathrm{U}$ atom ratio of approximately $10^{-3}$. From Table 5, the observed ${ }^{239} \mathrm{Pu} /{ }^{238} \mathrm{U}$ is on the order of $10^{-7}$ in the Paducah samples and on the order of $10^{-8}$ in the Portsmouth samples. If the assumption is made that the source of the Portsmouth $\mathrm{Pu}$ is the Paducah product, and that the mass fractionation of ${ }^{239} \mathrm{Pu}$ from ${ }^{238} \mathrm{U}$ is negligible, then loss of $\mathrm{Pu}$ in the Paducah cascade (or in transportation containers) from chemical fractionation is on the order of $90 \%$. This is not surprising, since volatile $\mathrm{PuF}_{6}$ is much more reactive than $\mathrm{UF}_{6}$, and is reduced to $\mathrm{PuF}_{4}$ by residual air (both $\mathrm{O}_{2}$ and $\mathrm{N}_{2}$ ) and by small amounts of $\mathrm{UF}_{4}$ contaminating the $\mathrm{UF}_{6}$. If the further assumption is made that the irradiated uranium made up a large fraction of the Paducah feed stock, then the observed ${ }^{239} \mathrm{Pu} /{ }^{238} \mathrm{U}$ values are consistent with $10^{-5}$ to $10^{-4}$ of the weaponsgrade $\mathrm{Pu}$ product being lost to the uranium fraction in the pre-cascade fuel reprocessing.

From Figure 4, the ${ }^{237} \mathrm{~Np} /{ }^{238} \mathrm{U}$ value in the discharged reactor fuel was approximately $10^{-5}$. From Table 5 , the observed ${ }^{237} \mathrm{~Np} / 238 \mathrm{U}$ is on the order of $5 \times 10^{-5}$ in the Paducah samples and on the order of $5 \times 10^{-6}$ in the Portsmouth samples. If the same assumptions apply to ${ }^{237} \mathrm{~Np}$ as apply to ${ }^{239} \mathrm{Pu}$, then loss of neptunium in the Paducah cascade is also on the order of $90 \%$; volatile $\mathrm{NpF}_{6}$ is intermediate in chemical reactivity between $\mathrm{UF}_{6}$ and $\mathrm{PuF}_{6}$, and a significant cascade loss would be expected. The fuel reprocessing was notably unsuccessful in removing ${ }^{237} \mathrm{~Np}$ from the Paducah feed stock, leaving essentially all of it with the uranium. This last observation reveals a detail about the post-processing conversion of product to volatile hexafluorides: While $\mathrm{UF}_{6}$ can be produced in high yield by a variety of strong fluorinating reagents (e.g. $\mathrm{BrF}_{3}, \mathrm{ClF}_{3}, \mathrm{SF}_{4}$, etc.) from several different uranium compounds at temperatures near $220^{\circ} \mathrm{C}$, the formation of $\mathrm{NpF}_{6}$ in high yields requires the reaction of $\mathrm{F}_{2}$ with lower $\mathrm{Np}$ fluorides at higher temperatures. This means that the $\mathrm{UF}_{6}$ production probably went through a $\mathrm{UF}_{4}$ intermediate. 
Although the relative concentrations of $\mathrm{Np}$ and $\mathrm{Pu}$ do not provide a conclusive signature, the reprocessing of spent fuel by means of a solvent extraction with tributyl phosphate (the PUREX process) provides for an efficient recovery of plutonium and a good decontamination from fission products, but leaves neptunium with the uranium. It would be interesting to look for long-lived ${ }^{129} \mathrm{I}$ or ${ }^{99} \mathrm{Tc}$ in the samples, both of which have fluorides that are volatile under the same conditions as $\mathrm{UF}_{6}$, and whose contamination levels might provide further clues to the reprocessing technique.

The ${ }^{237} \mathrm{~Np}$ and the residual $\mathrm{Pu}$ comprised a very small mass fraction, and only about $1 \%$ each of the total alpha radioactivity, of the Paducah feed material. However, the ${ }^{237} \mathrm{~Np}$ content approximately doubled the gamma-ray dose from the material, requiring increased shielding, and the presence of $\mathrm{Np}$ and $\mathrm{Pu}$ in the final product would require additional chemical clean-up for most non-reactor applications. Rather than permanently contaminating the cascade and fouling the plant product, it would have been preferable to clean the material thoroughly before producing the $\mathrm{UF}_{6}$ feed. A possible explanation for use of this less-thanideal strategy: Once a $\mathrm{UF}_{6}$-diffusion plant is in operation it cannot be stopped and restarted without enormous effort and expense and a large lead time. Feed of $\mathrm{UF}_{6}$ must be continuous. It seems likely that the use of contaminated uranium in the cascade was a symptom of a chronic uranium shortage, where stockpiles were insufficient to support independent programs for the production of weapons-grade $\mathrm{Pu}$ and highly-enriched uranium, and the input requirements of the enrichment cascades did not permit enough time for a lengthy decontamination of the feed stock.

The $\mathrm{Pu}$ activity ratios given in Table 7 can be corrected for enrichment in the cascade by assuming, once again, that the action of the cascade on the plutonium isotopes is similar in magnitude to the enrichment of uranium isotopes, and that the effect is roughly linear with mass. After each activity ratio was corrected for an arbitrary decay period of 20 years, the $3.2 \%$-enrichment ${ }^{235} \mathrm{U}$ BWR curve in Figure 2 was used to estimate the corresponding ${ }^{240} \mathrm{Pu} /{ }^{239} \mathrm{Pu}$ mass ratio. Both the ${ }^{238} \mathrm{Pu}$ and ${ }^{240} \mathrm{Pu}$ activities were corrected for the effect of the cascade on their enrichment (defined by $\pm 33 \%$ of the ${ }^{235} \mathrm{U}$ enrichment of the sample), the activity ratio was recalculated, and Figure 2 was again used to estimate ${ }^{240} \mathrm{Pu} /{ }^{239} \mathrm{Pu}$. This process was iterated until the value of ${ }^{240} \mathrm{Pu} /{ }^{239} \mathrm{Pu}$ converged.

The results of the calculation for each sample are given in Table 8. The atom ratio ${ }^{240} \mathrm{Pu} /{ }^{239} \mathrm{Pu}$ in the feed stock can be used with Figure 3 to determine the length of the reactor irradiation resulting in the $\mathrm{Pu}$ isotopic mix, in units appropriate for use with Figure 4. Both ${ }^{240} \mathrm{Pu} /{ }^{239} \mathrm{Pu}$ and ${ }^{241} \mathrm{Pu} /{ }^{239} \mathrm{Pu}$ (from Figure 3), corrected for the effect of the cascade on the samples, are given in Table 8; however, the ${ }^{241} \mathrm{Pu}$ data contains no correction for decay since reactor discharge. Considering the approximations inherent in computing the data in Table 8 , the resultant values 
for reactor irradiation length are remarkably consistent, yielding an average exposure of (1100 \pm 300$)$ MW-days (thermal) for the five samples.

Table 8. Plutonium Isotope Production and Reactor Irradiation Length (assuming 37.5 MW thermal power). The ${ }^{240} \mathrm{Pu} /{ }^{239} \mathrm{Pu}$ feed data is taken from the $3.2 \%$ enriched ${ }^{235} \mathrm{U}$ BWR curve in Figure 2; the ${ }^{238} \mathrm{Pu} /\left({ }^{239} \mathrm{Pu}+{ }^{240} \mathrm{Pu}\right)$ and ${ }^{240} \mathrm{Pu} /{ }^{239} \mathrm{Pu}$ cascade data are corrected for mass fractionation in the cascade and a 20-year decay period; the ${ }^{241} \mathrm{Pu} /{ }^{239} \mathrm{Pu}$ data are taken from Figure 3, and are corrected for the action of the cascade, but not for decay since reactor discharge.

\begin{tabular}{|c|c|c|c|c|c|}
\hline Sample & $\begin{array}{l}{ }^{238} \mathrm{Pu} /\left({ }^{239} \mathrm{Pu}+{ }^{240} \mathrm{Pu}\right) \\
\text { activity, corr. }\end{array}$ & $\begin{array}{l}\text { atoms } \\
\text { feed }\end{array}$ & $\begin{array}{c}{ }^{240} \mathrm{Pu} /{ }^{239} \mathrm{Pu} \\
\text { cascade }\end{array}$ & $\begin{array}{l}{ }^{241} \mathrm{Pu} /{ }^{239} \mathrm{Pu} \\
\text { dischg, casc. }\end{array}$ & $\begin{array}{l}\text { Irradiation } \\
\text { length }\end{array}$ \\
\hline 017 & 0.069 & $\overline{0.083}$ & 0.057 & 0.0083 & $\overline{43 \text { days }}$ \\
\hline $4-7$ & 0.017 & 0.036 & 0.031 & 0.0024 & days \\
\hline $94-7-19$ & 0.035 & 0.056 & 0.023 & 0.0018 & days \\
\hline $94-7-38$ & 0.039 & 0.060 & 0.073 & 0.0140 & 32 days \\
\hline $94-7-45$ & 0.027 & 0.048 & 0.057 & 0.0081 & $\frac{25 \text { days }}{29.6 \pm 8.7}$ \\
\hline
\end{tabular}

The irradiation lengths given in Table 8 can be used with Figure 4 to estimate the starting composition of the reactor-irradiated fraction of the cascade feed resulting in the analytical samples. It should be noted that at these low burn-ups, the atom ratios of ${ }^{234} \mathrm{U} /{ }^{238} \mathrm{U}$ and ${ }^{235} \mathrm{U} /{ }^{238} \mathrm{U}$ have not changed much from their values in natural uranium. The apparent enrichment of each uranium isotope relative to the cascade feed stock can be calculated from the data in Table 6: Enrichment $=\left({ }^{x} U / 238 U\right)_{\text {observed }} /\left({ }^{x} U /{ }^{238} U\right)_{\text {figure } 4}$, where $X$ is the atomic number of the isotope of interest. The enrichments of ${ }^{234} \mathrm{U},{ }^{235} \mathrm{U}$, and ${ }^{238} \mathrm{U}$, relative to ${ }^{238} \mathrm{U}_{\text {feed }}$ for each of the analytical samples are plotted in Figure 5 . The lines connecting the points are drawn free-hand. It is observed that the enrichment as a function of mass number is not even approximately linear for the Portsmouth samples, casting considerable doubt on the calculations resulting in their entries in Table 8. For the Paducah samples (used in most of the prior analyses) the linear-enrichment assumption is reasonable.

For each of the five samples, the calculated enrichment of ${ }^{236} \mathrm{U}$ is considerably less than that expected from the free-hand curves in Figure 5. For samples 94-717, 94-7-38, and 94-7-45, the ${ }^{236} \mathrm{U}$-enrichment is approximately $30 \%$ of that expected from the curves. For sample 94-7-14 the ${ }^{236} \mathrm{U}$-enrichment is $10 \%$ of expected, and for sample 94-7-19 it is only $4 \%$ of expected. If it is assumed that the ORIGEN2 calculation of ${ }^{236} \mathrm{U}$ production is accurate, then about $30 \%$ of the Paducah feed stock was irradiated uranium and 70\% was natural uranium. Sample 94-7-17 from Portsmouth exhibits the same isotopic fingerprint, thereby connecting it to the Paducah cascade. The other two Portsmouth samples originated from starting materials with a significantly smaller dilution of reactor fuel in natural 
uranium. This implies that Portsmouth received its feed from more than one source, and that the cascade was subdivided into different sections which received variable proportions of the different materials. An alternative explanation would be that the fraction of reactor-irradiated materials in the feed stock has changed over the years and samples 94-7-14 and 94-7-19 represent materials from a different operational era at the plant than do the other samples. The ${ }^{235} \mathrm{U}$ enrichments of 94-7-14 and 94-7-19 are higher than that in the other Portsmouth sample; given that feed or tails materials are more likely to be released into the environment than is product, these two samples may be representative of tails from a separate cascade, that was used in the production of highly-enriched uranium.

Samples can be age-dated using pairs of radionuclides that are linked by radioactive decay. It must be assumed that there existed a time in the past when the sample contained only parent activities, meaning that a chemical separation was performed to remove daughters. A gaseous-diffusion enrichment plant would appear to be an ideal facility for age determinations, since a likely mechanism for radioactive release to the environment would be the escape of volatile $\mathrm{UF}_{6}$ (and $\mathrm{PuF}_{6}$ ) into the air. Such a process would leave refractory $\mathrm{Pa}$, Th, $A c, R a$, and Am daughters and grand-daughters behind.

Table 5 gives concentrations for several pairs of nuclides that can be used to calculate specimen ages, which are given in Table 9 . The ages thus calculated from the measurements of relative quantities of volatile and refractory nuclides result in values of the age that are inconsistent and absurdly old. This implies that a chemical separation has indeed occurred, but that the refractory daughter nuclides have been dispersed after most of the volatile parent activities were removed. For example, consider 
Table 9. Pseudo-ages of the Analytical Samples, in years. The data are calculated from the indicated nuclide pairs, assuming that at the time defining the age, there was a complete absence of the radiogenic daughter. No corrections have been made for the radionuclide content of soil.

\begin{tabular}{|c|c|c|c|c|c|}
\hline $\begin{array}{l}\text { daughter/parent } \\
{ }^{230} \mathrm{Th} /{ }^{234} \mathrm{U} \\
{ }^{226} \mathrm{Ra} /{ }^{234} \mathrm{U} \\
{ }^{226} \mathrm{Ra} / 230_{\mathrm{Th}} *\end{array}$ & $\frac{94-7-14}{1640 \pm 160}$ & $\frac{94-7-17}{2490 \pm 210}$ & $\frac{94-7-19}{110 \pm 8}$ & $\begin{array}{l}\frac{94-7-38}{28600 \pm 3100} \\
754 \pm 62 \\
11_{ \pm 2}\end{array}$ & $\begin{array}{l}\frac{94-7-45}{16200 \pm 1500} \\
457 \pm 93 \\
7 \pm 3\end{array}$ \\
\hline $\begin{array}{l}{ }^{231} \mathrm{~Pa} /{ }^{235} \mathrm{U} \\
{ }^{227} \mathrm{Ac} /{ }^{235} \mathrm{U} \\
{ }^{227} \mathrm{Ac} /{ }^{231} \mathrm{~Pa}^{*}\end{array}$ & $\begin{array}{l}\leq 1200 \\
1200 \pm 600\end{array}$ & $\begin{array}{l}\leq 770 \\
\leq 250\end{array}$ & $\begin{array}{l}320 \pm 25 \\
\leq 53 \\
\leq 3\end{array}$ & $\begin{array}{l}900 \pm 110 \\
\leq 200 \\
\leq 8\end{array}$ & $\begin{array}{l}430 \pm 40 \\
130 \pm 40 \\
8 \pm 4\end{array}$ \\
\hline${ }^{232} \mathrm{Th} /{ }^{236} \mathrm{U}$ & $1 \times 10^{8}$ & $6 \times 10^{7}$ & $3 \times 10^{7}$ & $2 \times 10^{8}$ & $1 \times 10^{8}$ \\
\hline${ }^{241} \mathrm{Am} /{ }^{241} \mathrm{Pu}^{\#}$ & & & & & $30.5 \pm 0.9$ \\
\hline
\end{tabular}

the case of a large amount of $\mathrm{UF}_{6}$ stored in a container. There is a constant production of $\mathrm{Th}$ and $\mathrm{Pa}$ fluoride species through radioactive decay of the $U$ isotopes; these daughter compounds are non-volatile and tend to deposit on the walls of the container. If the $\mathrm{UF}_{6}$ is pumped away (leaving a small residue), a sample of the mixture of nuclides on the walls of the container would appear too old: It would normally be assumed that the daughters arose from the long-term decay of a small mass of parent rather than from the short-term decay of a large (missing) mass of parent. Another way this mixture could obtain is through the enrichment process itself; decay of uranium occurs throughout the enrichment cascade, and $\mathrm{ThF}_{4}$ and $\mathrm{PaF}_{5}$ would tend to accumulate in the diffusion barrier.

If the assumption is made that the ${ }^{230} \mathrm{Th}$ activity in each sample was produced from a steady-state ingrowth of ten years (the proper order of magnitude), then $3.5 \times 10^{4}$ atoms of ${ }^{234} \mathrm{U}$ were required to account for each atom of ${ }^{230} \mathrm{Th}$ observed. If, at the end of the accumulation period, all volatile $\mathrm{UF}_{6}$ were removed from the sample, the data in Table 5 can be used to estimate the loss in the process caused by chemical reactions producing non-volatile uranium compounds (e.g. $\mathrm{UO}_{2} \mathrm{~F}_{2}$ ). In the Paducah samples, approximately $0.05 \%$ of the uranium remained with its Th daughter. In Portsmouth samples 94-7-14 and 94-7-17, 0.5\% of the uranium remained. Sample 94-7-19 retained $10 \%$ of its original uranium content; it seems unlikely that the diffusion barrier would clog to this extent before it was changed out, or that this kind of accumulation on the walls of a container would not be recovered. Sample 94-7-19 is clearly more volatile in nature than are the other 
four samples, and may have had contributions through both a mechanical dispersal of daughters and a volatile gas release (see below).

The ages determined from the relative amounts of non-volatile daughter and grand-daughter activities $\left({ }^{230} \mathrm{Th}\right.$ and ${ }^{226} \mathrm{Ra}$, or ${ }^{231} \mathrm{~Pa}$ and ${ }^{227} \mathrm{Ac}$ ) are lower than expected, possibly as the result of the presence of a background due to the incorporation of dirt within the samples. The activity ratio of daughter/granddaughter is approximately 1.0 in soil, but it is much higher for samples in which the daughter was recently produced. The ${ }^{232} \mathrm{Th}$ content of soil can be used to explain the inordinately long ages derived from ${ }^{236} \mathrm{U}$, and provides a means of estimating the soil contribution to the radionuclide content of each sample. The Earth's crust contains an average of $12 \mathrm{ppm}{ }^{232} \mathrm{Th}$. If the soil contributions to the analytical samples contain thorium in the same proportion, Table 5 data can be used to calculate the soil components given in Table 10. (Also given are the original sample weights from Table 1). Soil contributed only a small fraction to the masses of the Portsmouth samples, all of which were collected magnetically. Paducah sample 94-7-38 was collected with a spatula, and only about a third of its mass could be accounted for by XRF analysis (Table 2); it therefore was indeed composed mostly of low-Z dirt. Paducah sample 94-7-45 was part of a larger sample from which nickel flakes were segregated during prescreening. Even though it was collected magnetically, it is not unreasonable to believe that half of the residue was dirt entrained during collection.

The ${ }^{238} \mathrm{U}$ content of soil is usually about $25 \%$ that of ${ }^{232} \mathrm{Th}$. On that basis, an estimate of the soil contribution to the uranium in each sample is given in Table 10. Comparing these values with data in Table 5, it is concluded that soil does not significantly perturb either the uranium content or the relative uranium isotopics of any of the samples. If it is assumed that the radiogenic daughters of the soil nuclides are in equilibrium with their parents, then corrections to Table 5 data for ${ }^{231} \mathrm{~Pa},{ }^{230} \mathrm{Th},{ }^{227} \mathrm{Ac}$, and ${ }^{226} \mathrm{Ra}$ can be calculated. These are also provided in Table 10. Any corrections to the ${ }^{230} \mathrm{Th}$ and ${ }^{231} \mathrm{~Pa}$ data are small and would not be significant given the precision of the measurements. The soil contribution to the ${ }^{226} \mathrm{Ra}$ content of the Paducah samples is quite high, however, on the order of $100 \%$; therefore the sample ages computed from the ${ }^{226} \mathrm{Ra} / 230 \mathrm{Th}$ pair (ca. 10 years) are much too low, in agreement with expectations. The corrections to ${ }^{227} \mathrm{Ac}$ are not large enough to explain the ages obtained from the ${ }^{227} \mathrm{Ac} / 231 \mathrm{~Pa}$ pair. There is clearly a problem with the ${ }^{231} \mathrm{~Pa}$ data.

If it is valid to assume that the mix of ${ }^{231} \mathrm{~Pa}$ and ${ }^{230} \mathrm{Th}$ in each sample arose from the decay of uranium of the same composition as that in the samples, then the same (incorrect) ages should be 
Table 10. Soil Contributions to the Radionuclide Contents of PUBLIC Samples, calculated from the ${ }^{232} \mathrm{Th}$ contents given in Table 5. Uranium content is assumed to be $25 \%$ of the thorium content.

$\begin{array}{llllll} & \frac{94-7-14}{7.0 \mathrm{~g}} & \frac{94-7-17}{1.4 \mathrm{~g}} & \frac{94-7-19}{3.3 \mathrm{~g}} & \frac{94-7-38}{4.9 \mathrm{~g}} & \frac{94-7-45}{20.5 \mathrm{~g}} \\ \text { sample wt } & 0.12 \mathrm{~g} & 0.12 \mathrm{~g} & 0.07 \mathrm{~g} & 4.8 \mathrm{~g} & 10.5 \mathrm{~g} \\ \text { soil content } & 9.1 \mathrm{E} 14 & 9.1 \mathrm{E} 14 & 5.1 \mathrm{E} 14 & 3.6 \mathrm{E} 16 & 8.0 \mathrm{E} 16 \\ \text { soil U atoms } & \geq 0.5 \% & \geq 0.2 \% & 0.03 \% & 4.3 \% & 3.2 \% \\ { }^{231} \mathrm{~Pa} \text { soil frac } & 1.0 \% & 0.2 \% & 0.2 \% & 0.5 \% & 0.3 \% \\ { }^{230} \mathrm{Th} \text { soil frac } & & & \geq 0.4 \% & \geq 23 \% & 15 \% \\ { }^{227} \mathrm{Ac} \text { soil frac } & & & & 100 \% & 85 \% \\ \text { 226 Ra soil frac } & & & & \end{array}$

calculated from both the ${ }^{230} \mathrm{Th} /{ }^{234} \mathrm{U}$ and ${ }^{231} \mathrm{~Pa} /{ }^{235} \mathrm{U}$ nuclide pairs. This is clearly not the case. With the exception of sample $94-7-19$, the ${ }^{231} \mathrm{~Pa}$ ages are significantly shorter than the ${ }^{230} \mathrm{Th}$ ages, indicating that ${ }^{231} \mathrm{~Pa}$ was removed from the samples after release. Another way to look at this: The atom ratio ${ }^{235} \mathrm{U} /{ }^{234} \mathrm{U}$ in the material whose decay resulted in the non-soil radionuclides in the samples can be calculated from the uranium half lives and the ${ }^{231} \mathrm{~Pa} /{ }^{230} \mathrm{Th}$ atom ratio. These data are given in Table 11, along with the direct measurement of ${ }^{235} \mathrm{U} /{ }^{234} \mathrm{U}$ derived from Table 6. Again, with the exception of sample 94-7-19, there is less ${ }^{231} \mathrm{~Pa}$ in the samples than there should be. One might consider a possible explanation to be that the uranium composition of the samples is unrelated to the daughter content; however, this could not explain either of the Paducah samples, where the derived values of ${ }^{235} \mathrm{U} / 234 \mathrm{U}$ are an order of magnitude lower than would be produced by gaseous diffusion of the known starting materials.

An explanation for the loss of ${ }^{231} \mathrm{~Pa}$ is in its aqueous chemistry. $\mathrm{PaF}_{5}$ is soluble in water (in fact, deliquescent), while $\mathrm{AcF}_{3}$ and $\mathrm{ThF}_{4}$ are not. The 94-7-14 and 94-7-17 samples from Portsmouth may have been moist, resulting in partial leaching of ${ }^{231} \mathrm{~Pa}$. The ${ }^{231} \mathrm{~Pa}$ content of the Paducah samples is so severely reduced that it seems likely that water was used in the process that resulted in the dispersal of the material; both samples were collected well above floor level, indicating the possible use of pressurized water. Since uranyl fluoride $\left(\mathrm{UO}_{2} \mathrm{~F}_{2}\right.$, the product of the reaction of $\mathrm{UF}_{6}$ with moist air) is also water soluble, it is likely that the process uranium loss calculated above for Paducah samples is actually an order of magnitude too low, and that Portsmouth and Paducah both suffered from process losses on the order of $1 \%$.

The mix of activities in sample 94-7-19 is difficult to explain. The relative proportions of ${ }^{231} \mathrm{~Pa}$ and ${ }^{230} \mathrm{Th}$ in the material are inconsistent with the uranium isotopics, even with a correction for different solubilities. Much of the radionuclide content of 
Table 11. Evidence of Chemical Activity in PUBLIC Samples After Release. Calculated atom ratio ${ }^{235} \mathrm{U} / 234 \mathrm{U}$ from Table 6 ("direct") and from relative amounts of ${ }^{231} \mathrm{~Pa}$ and ${ }^{230} \mathrm{Th}$ given in Table 5 ("daughter"). Natural uranium ${ }^{235} \mathrm{U} /{ }^{234} \mathrm{U}=$ 132.

$\begin{array}{llllll} & \frac{94-7-14}{167 \pm 2} & \frac{94-7-17}{176 \pm 2} & \frac{94-7-19}{97 \pm 1} & \frac{94-7-38}{169 \pm 2} & \frac{94-7-45}{164 \pm 2} \\ \text { direct } & \leq 125 & \leq 56 & 290 \pm 20 & 6.3 \pm 0.7 & 4.8 \pm 0.4\end{array}$

the sample may have been leached from other materials by water, which would explain the elevated levels of uranium and ${ }^{231} \mathrm{~Pa}$ relative to other activities.

The only age in Table 9 that is consistent with the samples being generated during the CIP is the ${ }^{241} \mathrm{Am} /{ }^{241} \mathrm{Pu}$ value given for sample $94-7-45$. If the ${ }^{241} \mathrm{Am}$ component of the sample was the result of its long-term accumulation in barrier material as (partially) volatile $\mathrm{PuF}_{6}$ flowed by, the computed age would be significantly higher than the actual age. In fact, it is impossible to calculate an age for probable-barrier samples $94-7-14$ and $94-7-17$ from the calculated ${ }^{241} \mathrm{Pu}$ data in Table 8 because there is more measured ${ }^{241} \mathrm{Am}$ in the samples than can be attributed to full decay. However, Table 2 indicates that potential barrier material (nickel) made up less than 10\% of sample 94-7-45. It seems likely that the radionuclides in this specimen were introduced with debris components that were not barrier-related. These might be fragments from the walls of a container used for storage of tails material upon which a large fraction of the highlyreactive $\mathrm{PuF}_{6}$ had reduced to a non-volatile compound. This would result in an age value that was only slightly too old. The midpoint in plant operations between start up $(\sim 1955)$ and the CIP $(\sim 1979)$ is 1967, or an age of 27 years.

\section{SUMMARY}

The radionuclide contents of samples taken in the PUBLIC site inspections not only reveal information about plant operations in Portsmouth and Paducah, but also about the U.S. weapons complex as a whole:

Feed stock to the enrichment plants contained a significant amount of uranium that had been irradiated in a natural-uranium-fueled graphite-moderated reactor for the purpose of producing weapons-grade plutonium. Recovery of Pu from this fuel was probably accomplished with the PUREX process, leaving about $10^{-3} \%$ of the plutonium and virtually all of the byproduct ${ }^{237} \mathrm{~Np}$ with the uranium. The use of this incompletely decontaminated material in the cascade feed was probably required by a uranium shortage occurring sometime after the plants started operations. The $\mathrm{UF}_{6}$ cascade feed stock was produced through the action of free fluorine on $\mathrm{UF}_{4}$ rather with other fluorinating agents. 
The same isotopic signatures exist in the Paducah and Portsmouth feed stocks; however, feed of a different signature was also used in Portsmouth, implying the presence of more than one enrichment cascade. This separate cascade had tails with a moderate enrichment in ${ }^{235} \mathrm{U}$, as would be expected from a process for the production of highly-enriched (weapons-grade) uranium. Cascade losses of uranium in both Portsmouth and Paducah were on the order of 1\%; about $90 \%$ of the plutonium and neptunium introduced with the Paducah feed stock were lost in the cascade.

The site contamination at both plants took place by dispersion of non-volatile activities rather than through leaks of volatile $\mathrm{UF}_{6}$ into the gas phase. In the Portsmouth facility this took place mechanically, while in the Paducah facility water was used. It proved to be difficult to age date any of the operations at the plant; decay of ${ }^{241} \mathrm{Pu}$ relative to the other $\mathrm{Pu}$ isotopes and ingrowth of ${ }^{241} \mathrm{Am}$ indicate enrichment operations in Paducah in the 1950's and 1960's.

\section{ACKNOWLEDGEMENTS}

Thanks are due to P. Grant and R. Whipple of the Forensic Science Center for collecting samples in the site inspections, and performing the sample prescreening at LLNL. R. Nuckolls, A. Volpe, B. Ruiz, C. Velsko, and J. Wild performed some of the analytical measurements on radiochemical fractions, without which there would be little data to interpret. The hospitality and helpfulness of the staffs of both the Portsmouth and Paducah facilities during the site inspections is also gratefully acknowledged. 


\section{FIGURE CAPTIONS}

1. Results of ORIGEN2 calculations for several reactor types, correlation between plutonium observables: ${ }^{238} \mathrm{Pu} /\left({ }^{239} \mathrm{Pu}+{ }^{240} \mathrm{Pu}\right)$ activity vs. ${ }^{240} \mathrm{Pu} /{ }^{239} \mathrm{Pu}$ mass.

2. Results of ORIGEN2 calculations for Boiling Water reactors, and the effect of variable fuel enrichment on $\mathrm{Pu}$ observables. Circles are derived from data in Table 7 for samples 94-7-38 and 94-7-45. After correction for the effects of 20 years of radioactive decay (arbitrary) and mass fractionation in the cascade, adjusted points are represented by triangles.

3. ORIGEN2 calculation of the relative production of the indicated plutonium isotopes as a function of irradiation time at a power level of $37.5 \mathrm{MW}$ (thermal) in a hypothetical natural-uranium-fueled BWR. Also shown is the production of ${ }^{239} \mathrm{Pu}$ relative to residual ${ }^{238} \mathrm{U}$ in the fuel. Circular data points are for sample 947-45, from Table 7. Triangular points are these data corrected for mass fractionation in the cascade. Arrows on 241/239 data indicate that corrections for the decay of short-lived ${ }^{241} \mathrm{Pu}$ would adjust the data closer to the appropriate curve. The data are plotted at irradiation times defined by the values of 240/239.

4. ORIGEN2 calculation of the relative production of the indicated uranium isotopes (and ${ }^{237} \mathrm{~Np}$ ) as a function of irradiation time at a power level of $37.5 \mathrm{MW}$ (thermal) in a hypothetical natural-uranium-fueled BWR. Computation analogous to Figure 3.

5. Enrichment of uranium isotopes relative to cascade feed stock, defined as $\left({ }^{x} U /{ }^{238} U\right)_{o b s} /\left({ }^{x} U /{ }^{238} U\right)_{\text {feed }}$, for the five PUBLIC samples. Curves are free-hand. 


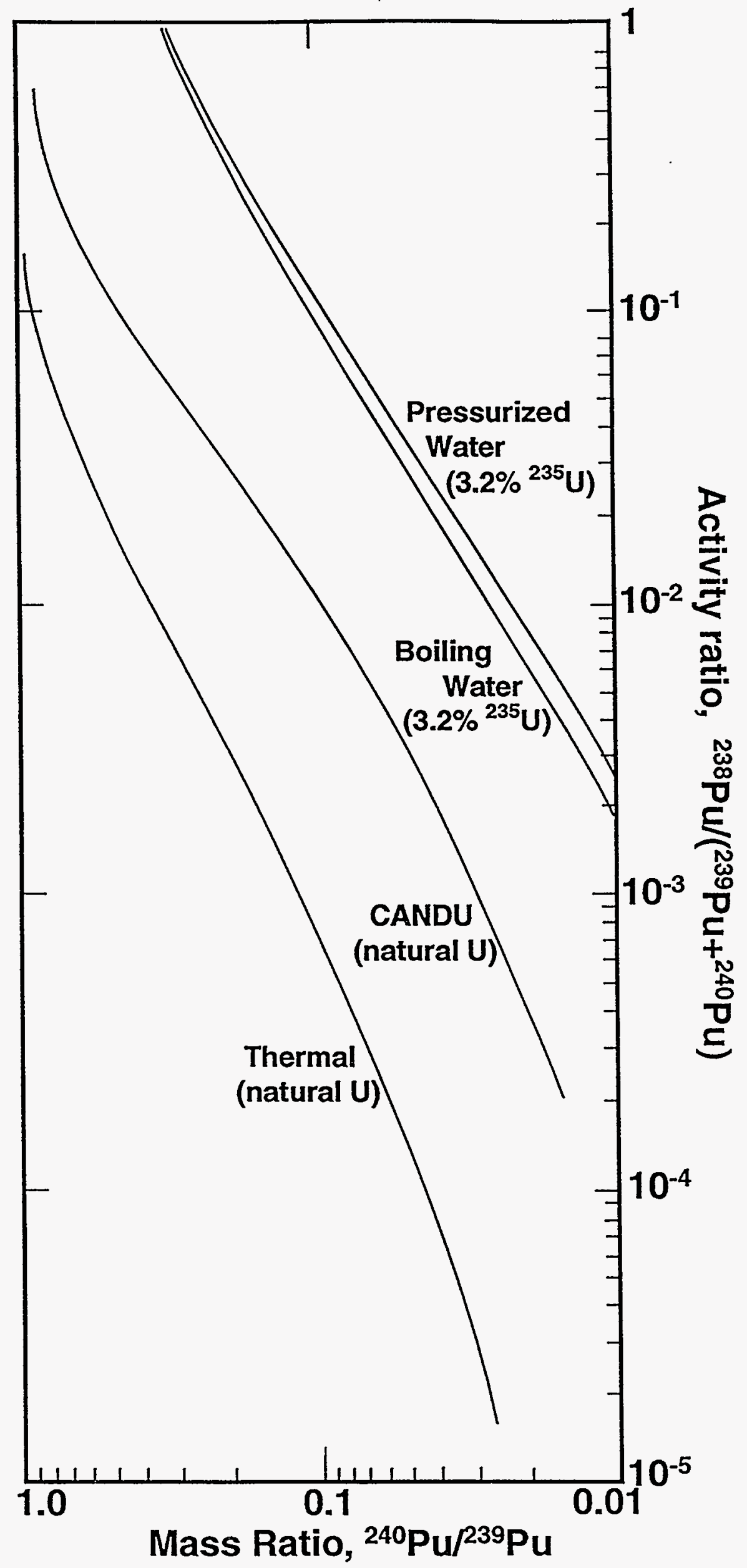




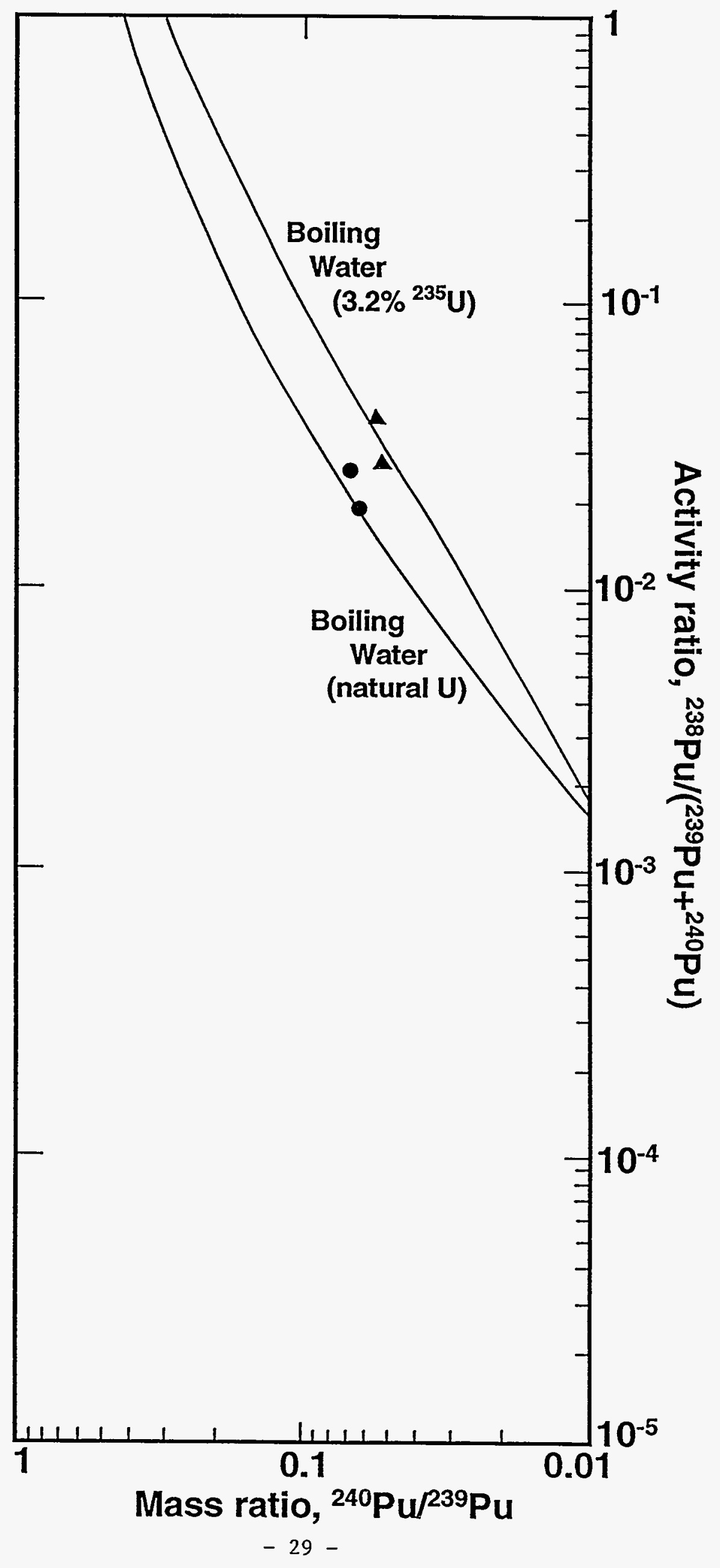

figure 2 


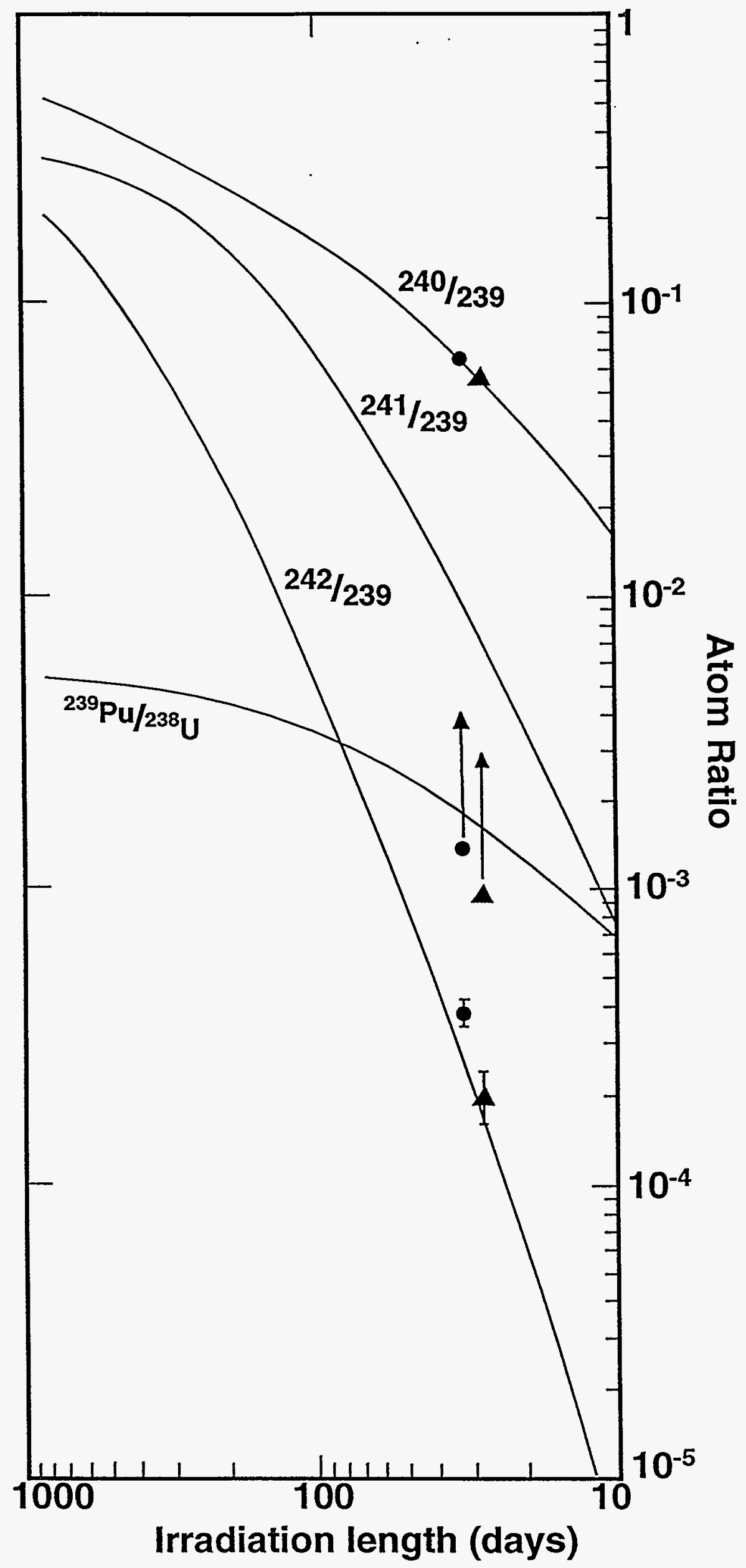

figure 3 


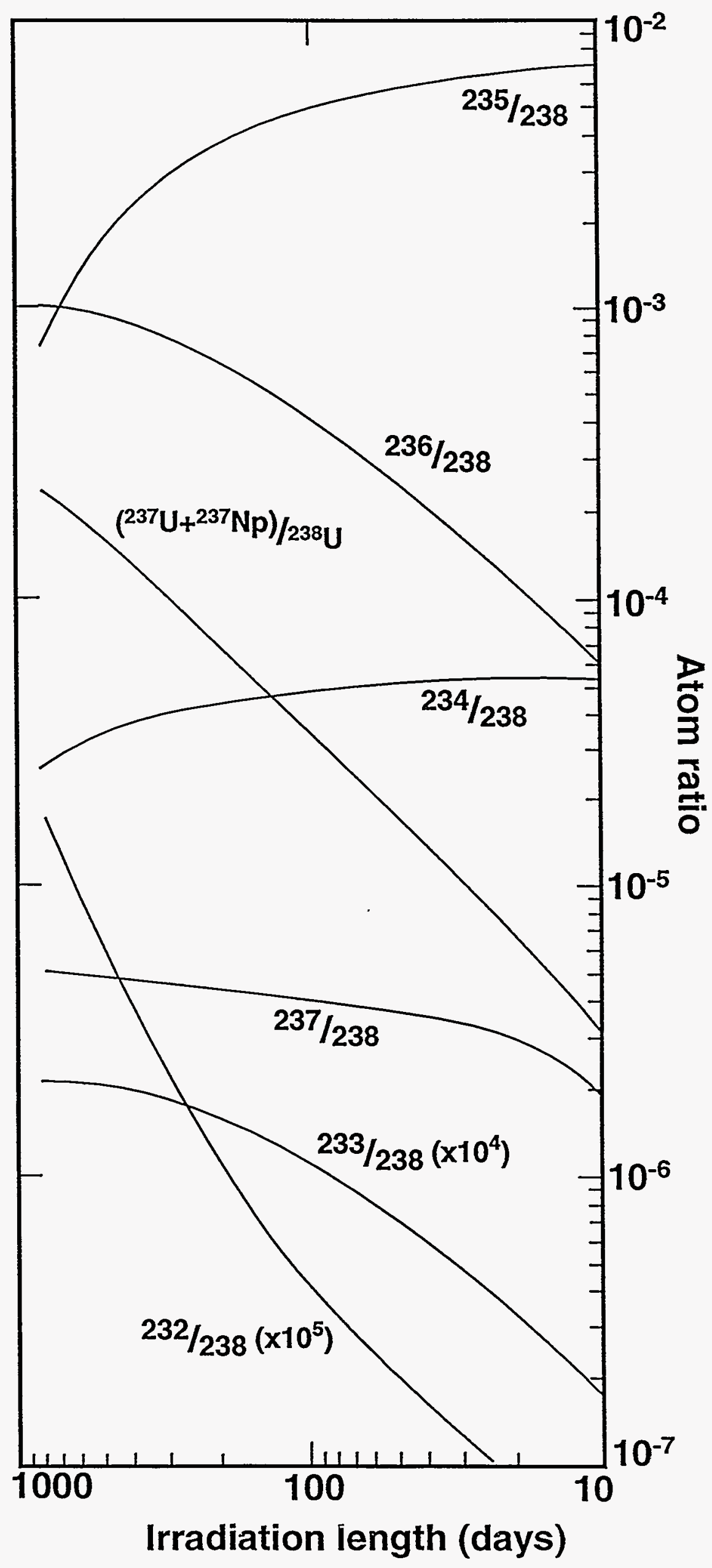

- 31 -

figure 4 


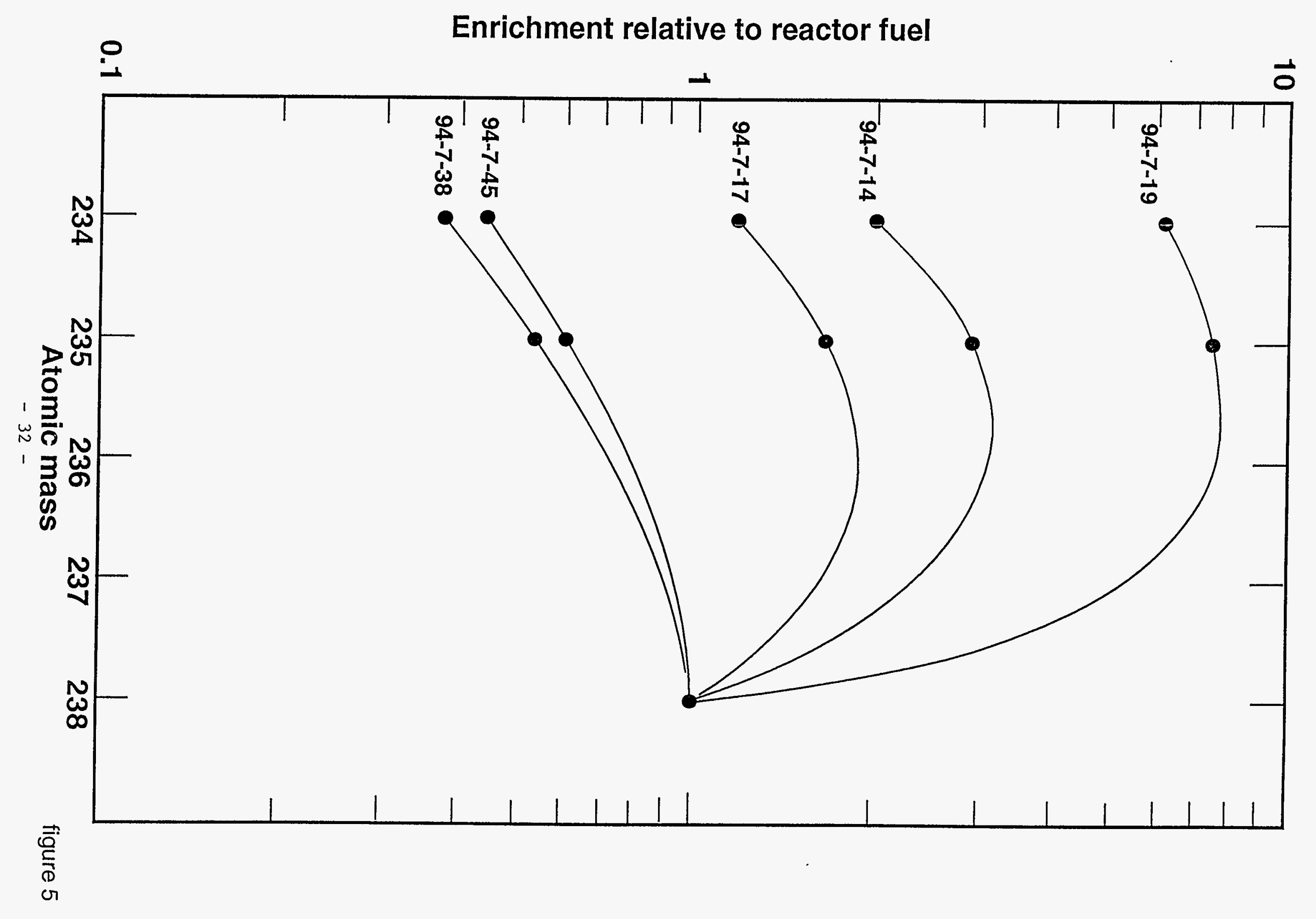

